\title{
Análisis de la formación académica del profesorado: El caso del periodo sabático en el Tecnológico Nacional de México durante los años académicos 2012-2018
}

\author{
Analysis professorship academic training: the case of the sabbatical leave at National \\ Technological Mexico during the academic years 2012-2018
}

\section{Análise da formação acadêmica do corpo docente: o caso da licença sabática no Tecnológico Nacional do México durante os anos acadêmicos 2012-2018}

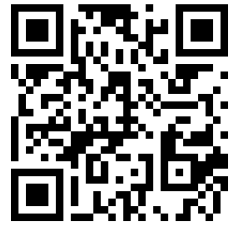

Corregido • Revised • Revisado: 18 / 03 / 2020

Aceptado • Accepted • Aprovado: 07 / 07 / 2020

\begin{abstract}
Resumen: El objetivo de este artículo de investigación es analizar la formación académica del profesorado que se beneficia en el programa del periodo sabático en el Tecnológico Nacional de México (TecNM). Para este propósito se realizó una investigación no experimental de corte cuantitativo, con diseño transversal y descriptivo a las solicitudes y reportes finales de $n=3,179$ personas que presentaron sus aplicaciones durante los años académicos 2012-2018; esta muestra representa el $30.97 \%$ del total de 10264 personas de tiempo completo pertenecientes a 132 instituciones federales del TecNM. Los principales resultados encontrados en la muestra de $n=3179$ del periodo sabático
\end{abstract}


http://doi.org/10.15359/ree.24-3.4

http://www.una.ac.cr/educare

educare@una.cr

son: el 34.22\% (1 088) son mujeres y el 65.78\% (2 091) son hombres y el 71.98\% (2 288) fortalece la elaboración de apuntes, manuales de prácticas o libros; la eficiencia terminal es del 88.44\% (2 357 personas en estado de liberación); el 36.7\% (1 167) de las personas tienen una edad de 58 a 68 años; el $85.91 \%$ (2 695) realiza sus actividades en su propia institución; y en promedio el 4.85\% (498) del total de 10264 personas docentes de tiempo completo disfruta anualmente este beneficio. También se propone que, en el periodo sabático del TecNM, se promueva la participación de las generaciones más jóvenes, se impulse la movilidad del profesorado al extranjero y se nivele la participación en todos sus programas académicos. Finalmente, se concluye que el TecNM invierte un recurso importante en la formación académica de su profesorado a través de 18 programas académicos de la estrategia del periodo sabático, con la finalidad de mantener su planta docente de calidad.

Palabras claves: Actualización de los conocimientos; desarrollo de las habilidades; licencia de enseñanza; perfeccionamiento; programa de formación del profesorado.

Abstract: This research article aims to analyze the academic training of the professors that enjoy a sabbatical leave at the National Technological Institute of Mexico (TecNM). For this purpose, quantitative non-experimental research was conducted, with a transversal and descriptive design to the applications and final reports of $n=3,179$ persons who submitted their applications during the academic years 2012-2018. This sample represents $30.97 \%$ of the total of 10,264 full-time academic teaching personnel, belonging to 132 federal institutions of TecNM. The major results found in the sample of $n=3,179$ from the sabbatical leave are: $34.22 \%(1,088)$ are women and $65.78 \%(2,091)$ are men; $71.98 \%(2,288)$ reinforce the elaboration of notes, training manuals, or books; the terminal efficiency is $88.44 \%(2,357$ persons in a state of release); $36.7 \%(1,167)$ of the persons are aged between 58 and 68; 85.91\% (2,695) carry out its activities in its institution; an average of $4.85 \%(498)$ of the total 10,264 full-time academic teaching personnel enjoy this benefit annually. It is also proposed that, during the sabbatical leave at TecNM, the participation of the younger generations is promoted, that the teacher mobility abroad is encouraged, and that participation in all its academic programs is leveled. Finally, it is concluded that the TecNM invests an important resource in the academic training of its professorship through the 18 academic programs of the sabbatical leave, to maintain its quality academic teaching personnel.

Keywords: Refresher courses; skills development; teacher leave; further training; teacher education curriculum.

Resumo: O objetivo deste artigo de pesquisa é analisar a formação acadêmica da cátedra que se beneficia de uma licença sabática no Tecnológico Nacional do México (TecNM). Para isso, foi realizada uma pesquisa quantitativa não experimental, com um desenho transversal e descritivo às candidaturas e relatórios finais de $n=3.179$ pessoas que apresentaram suas candidaturas durante os anos acadêmicos 2012-2018. Esta amostra representa 30,97\% do total de 10.264 docentes acadêmicos em tempo integral pertencentes a 132 instituições federais do TecNM. Os principais resultados encontrados na amostra de $n=3.179$ da licença sabática são: 34,22\% (1.088) são mulheres e 65,78\% (2.091) são homens; $71,98 \%$ (2.288) reforçam a elaboração de notas, manuais de treinamento ou livros; a eficiência terminal é de $88,44 \%$ (2.357 pessoas em um estado de liberação); 36.7\% (1.167) das pessoas têm entre 58 e 68 


\begin{abstract}
anos; $85,91 \%$ (2.695) realizam suas atividades em sua própria instituição; e uma média de 4,85\% (498) do total de 10.264 docentes acadêmicos em tempo integral desfrutam desse benefício anualmente. Também se propõe que, durante a licença sabática no TecNM, se promova a participação das novas gerações, se estimule a mobilidade dos professores no exterior e se nivele a participação em todos os seus programas acadêmicos. Finalmente, conclui-se que o TecNM investe um importante recurso na formação acadêmica de seu corpo docente através dos 18 programas acadêmicos da licença sabática, a fim de manter a qualidade de seu pessoal docente acadêmico.
\end{abstract}

Palavras-chave: Cursos de atualização; desenvolvimento de habilidades; licença do professor; formação contínua; programa de formação de professores.

\title{
Introducción
}

Kimball (1978), Ossa Londoño (1999) y Pereira de Homes y Suárez Amaya (2003), coinciden en que el origen del periodo sabático se encuentra en la cultura judaica y hace referencia a un descanso, el cual puede ser el séptimo día después de seis días de trabajo rutinario o el séptimo año en el cual no se cultivaba la tierra. Esta práctica que se introdujo como un permiso, licencia o periodo sabático en las universidades de los Estados Unidos de América (EUA), a finales del siglo XIX, mantenía el concepto de descanso cada séptimo año, es decir, el profesorado descansa y no se espera que produzca una cosecha de la población estudiantil durante ese año (Crosby Eells y Hollis, 1962). El sabático se estableció como un séptimo año de descanso después de seis años de rutina de trabajo, con el propósito del rejuvenecimiento y restauración de la facultad (Zahorski, 1994, citado por Kang y Miller, 1999), en consecuencia, el sabático es un tiempo de ausencia para estudiar, descansar o viajar, otorgado en intervalos de tiempo (originalmente cada siete años) al profesorado o personal administrativo con un sueldo parcial o fijo. Crosby Eells y Hollis (1962) mencionan que el primer programa establecido para el sabático fue en la Universidad de Harvard en el año de 1880 e inaugurado por su presidente Charles W. Eliot como una medida de reforma.

Diversas universidades de varios países han adoptado, con sus variantes propias, la implementación de un sabático que beneficie a la institución y a su profesorado. En México, se propone como política de Gobierno Federal que se garantice el derecho a la educación con calidad. Parte de ésta es generar diversos programas que impulsen la actualización, fortalecimiento y superación académica del profesorado de educación superior. Con base en ella, el TecNM, desde su modelo educativo vigente, impulsa la actualización profesional, formación de docentes y de capital humano para la investigación (Dirección General de Educación Superior Tecnológica [DGEST], 2012). En la propuesta de su nuevo modelo educativo, actualmente en fase de construcción y desarrollo, se propone un eje de fortalecimiento al profesorado con el propósito de permitir la mejora continua y el perfeccionamiento de sus competencias docentes 
http://doi.org/10.15359/ree.24-3.4

http://www.una.ac.cr/educare

educare@una.cr

en los ámbitos de la docencia, tutoría, investigación, gestión y vinculación (Tecnológico Nacional de México [TecNM], 2018b). Una de las estrategias que, actualmente, el TecNM establece para llevar a cabo la mejora continua del profesorado es el periodo sabático, el cual tiene como objetivo actualizar y fortalecer la superación académica de la planta docente (TecNM, 2016); históricamente el TecNM otorgó el primer sabático en 1986 y desde esa fecha hasta el 2018, se han beneficiado a 11380 personas.

El objetivo de esta investigación fue analizar la formación académica del profesorado del TecNM que se beneficia con un periodo sabático, durante los años académicos 2012-2018, considerando las variables de sexo, edad, distribución geográfica en México y el extranjero, lugar de estancia, tipo de institución y los programas académicos. El trabajo se encuentra divido de la siguiente manera: la primera sección presenta una revisión de la bibligrafía acerca del periodo sabático (en el texto se empleará indistintamente sabático o periodo sabático para referirse a lo mismo), en la cual se abordan los principales conceptos, propósitos y beneficios, así como algunas experiencias en diversas instituciones del continente americano; la segunda sección proporciona los principales datos institucionales del TecNM, así como la descripción de su sabático y el diseño metodológico para la obtención y revisión de los datos; la tercera presenta el análisis de resultados; en la cuarta se lleva a cabo la discusión del análisis de los resultados; y en la última se exponen las principales conclusiones como producto de este trabajo de investigación.

\section{Revisión bibliográfica acerca del periodo sabático}

En esta sección se revisa la bibliografía referente a las principales definiciones del sabático, así como la descripción de sus propósitos y beneficios.

\section{Definición}

De acuerdo con el Diccionario de Oxford, la licencia sabática se define como un tiempo de permiso pagado que se le concede al profesorado u otro personal para estudiar o viajar, tradicionalmente un año por cada siete años trabajados. Para Parent Jacquemin (1998) representa un descanso o receso de la rutina, es decir, un tiempo en el cual el profesorado se separa de sus actividades cotidianas que realiza en la universidad y se aleja de todas las relaciones de su cuerpo directivo y la comunidad universitaria; mientras que para Ramírez Bacca (2013), desde el ámbito de la investigación es una liberación de la carga docente durante un tiempo de doce meses. Los 4 cuatro aspectos fundamentales que el periodo sabático contempla para las personas de una institución de educación o una empresa son: 
http://doi.org/10.15359/ree.24-3.4

1) Compensación, que hace referencia a un beneficio de goce de sueldo y prestaciones laborales.

2) Espacio definido, un tiempo no mayor a un año con liberación o separación de sus actividades ordinarias docentes o laborales.

3) Propósito, en el cual las personas realizan actividades académicas, laborales, de investigación y extensión, para el desarrollo y superación tanto personal como de la institución.

4) Mejora continua, la cual implica un compromiso ético de las personas para regresar a su institución o empresa para un servicio docente o laboral, ya sea igual o mayor al tiempo de duración de su sabático.

En México el TecNM, el Instituto Politécnico Nacional (IPN) y la Universidad Nacional Autónoma de México (UNAM) son algunos ejemplos de instituciones que otorgan el beneficio a su profesorado del goce de sueldo durante un tiempo de seis o doce meses: garantizan a la planta docente mantener sus derechos laborales y antigüedad de servicio; el profesorado realiza un proyecto de investigación, una actividad académica o estudios de posgrado y, una vez que concluye su sabático, se integra a su institución para revitalizarla a través de su experiencia, nuevos conocimientos y sus competencias mejoradas. En el sector empresarial, de acuerdo con Diversity Best Practices (DBP) (2018), empresas como Deloitte, PwC y Boston Consulting Group (consultoría y asesoría legal), Adobe y Autodesk (desarrollo de software), y General Mills (productos alimenticios) también ofrecen a su personal el beneficio del sueldo en un tiempo de 4 a 12 semanas. La empresa consultora mundial en Tecnología de la Información, Cisco Systems and Accenture Ltd., también ha implementado programas para su personal de un año sabático, con la finalidad de reducir la cantidad de recortes. Estos programas ofrecen, a su personal, desde la mitad hasta un tercio de su salario (Carr y Tang, 2005).

\section{Propósitos}

Zahorski (1994) realizó un estudio informal de 100 instituciones, donde utilizando declaraciones de política como su marco de referencia, concluyó que los cuatro propósitos de un sabático son: a) enriquecimiento académico, b) perfeccionamiento de la enseñanza, c) promoción de cursos y desarrollo curricular, y d) mejoramiento del rendimiento artístico y el crecimiento creativo.

Sima y Denton (1995) realizaron un estudio en una universidad pública de investigación en el medio oeste de EUA durante los años académicos de 1991-1993, usaron 193 aplicaciones de sabático por la comunidad de la institución y 125 reportes finales de sabático y, a través 
http://doi.org/10.15359/ree.24-3.4

http://www.una.ac.cr/educare

educare@una.cr

de su esquema de trabajo, identificaron siete propósitos: a) aprendizaje de una nueva técnica de investigación, b) desarrollo de investigación, c) dirección de investigación, d) estudios, e) escritura de libro, monografía o artículo de revista, f) dirección de revisiones, diseño de procedimientos o creación de un trabajo artístico, y g) desarrollo de cursos o currículo.

Sarason (1990) explicó en su trabajo otro propósito del sabático: un cambio en el equilibrio de las responsabilidades de la institución; además informó que no es un regalo de la universidad, sino una liberación de responsabilidades docentes y administrativas de las personas, con la finalidad de revisar sus logros pasados, o realizar un balance personal, o moverse en nuevas direcciones de enriquecimiento, o viajar a algún lugar para aprender nuevas cosas.

Academic Senate for California Community Colleges (ASCCC) (2007) realizó un estudio con 102 colegios de California considerando los enfoques académico e institucional, el cual utilizó encuestas donde se preguntaba sobre las razones para conceder un sabático, así como sus beneficios al obtenerlo. La ASCCC encontró cinco propósitos por los cuales la institución otorgó sabático: a) oportunidad bien merecida para el descanso y la recreación, b) oportunidad para la educación adicional, la formación, o la experiencia de trabajo en el campo de la persona, c) recompensa por los años de servicio a la comunidad estudiantil, d) forma vital de desarrollo profesional, y e) oportunidad para desarrollar nuevos programas y currículos. Además, la mayoría de las instituciones reconocieron los siguientes factores para justificar su otorgamiento: generar un nuevo producto (documento escrito, estudio u obra de arte), enriquecimiento profesional (viajes o pasantías), cursos y la terminación de un grado o certificación.

Considerando como ejemplo los estudios anteriores, lo cual no es limitativo, se puede resumir que los principales propósitos del periodo sabático son:

1) Enriquecimiento académico: investigación y redacción de revistas o libros.

2) Educación continua: terminación de estudios de posgrado, certificaciones y cursos.

3) Desarrollo curricular: mejora continua del currículo y perfeccionamiento de la enseñanza.

4) Movilidad: viajes, estancias, pasantías y estadías.

\section{Beneficios}

Los beneficios del periodo sabático son analizados desde dos puntos de vista: la administración de la institución y el personal beneficiado. 


\section{Beneficios individuales}

Un estudio realizado por Sorcinelli (1986), en la Universidad de Indiana a través de entrevistas y cuestionarios aplicados a 112 personas del personal docente (titulares, asociados y auxiliares), identificó que el sabático y las licencias representan un beneficio para el crecimiento real de su área de conocimiento, pues se aprenden competencias nuevas o una renovación/reorientación para la carrera profesional, se asumen nuevos retos y responsabilidades en la universidad; por lo anterior, las personas encuestadas recomendaron que hubiera una mayor flexibilidad en los procedimientos y políticas de la universidad para otorgar el beneficio del sabático.

Zahorski (1994) llevó a cabo entrevistas de manera individual con la comunidad académica, donde se preguntaba qué beneficios obtuvieron del sabático, todas las respuestas se clasificaron en seis beneficios: a) agente de rejuvenecimiento y renovación que ayudó en el aula, lo cual proporciona un enorme potencial restaurador en lo físico, mental y espiritual; b) tiempo de reflexión sobre el equilibrio entre la vida personal y profesional, lo cual ayuda a reorientar metas de enseñanza, investigación y servicio; c) obtener una nueva perspectiva de su trabajo, competencias y habilidades, esto ayuda a generar nuevas ideas; d) expansión de la red profesional, que contribuye a ampliar las oportunidades de colaboración en proyectos de investigación o docencia con nuevos cuerpos colegiados profesionales; e) estar actualizado en la disciplina, en los campos de cambio rápido, con una mayor flexibilidad para visitar laboratorios o sitios de campo que sean de vanguardia; y f) mejorar la enseñanza, a través de las experiencias que se incorporan en el aula.

Sima y Denton (1995), en busca de beneficios académicos durante los años de 1991 y 1993, examinaron los reportes finales del sabático de 125 miembros de una universidad pública de investigación en el medio oeste de EUA. Los resultados encontrados exhiben una producción de 42 libros o manuscritos, 26 capítulos de libro, 4 monografías, 91 artículos publicados, 65 artículos enviados para su publicación, \$1 315000 en subvenciones de investigación aseguradas, 36 propuestas de subvenciones, 94 presentaciones o conferencias invitadas, 13 cursos nuevos o revisados, 2 composiciones musicales, 1 conferencia y 1 reporte analítico.

Carr y Tang (2005) realizaron un estudio de las formas en las que se realiza el sabático en las empresas Perkins Coie, Cisco Systems and Accenture Ltd., Boston Consulting Group, Inc.'s, Microsoft, Lockheed Martin Corp., Tandem Computers, Inc. Uno de los principales hallazgos encontrados es que la mayoría del personal en una empresa, al regresar de su sabático, se siente renovado y rejuvenecido, lo cual lo convierte en más productivo que antes. Otras personas reportaron que lo emplearon para viajar, escribir una novela, ser voluntarios con organizaciones sin fines de lucro, o aprender una nueva habilidad como tocar el piano o construir su casa.

Iravani (2011) analizó los impactos del sabático a partir de las respuestas proporcionadas por 120 miembros de una facultad de la Universidad de Teherán, los cuales clasificó en cinco 
http://doi.org/10.15359/ree.24-3.4

http://www.una.ac.cr/educare

educare@una.cr

componentes ordenados de mayor a menor porcentaje de la variación total. De estos cinco componentes, cuatro se pueden considerar de beneficio individual; el primero llamado profesionalismo, hace referencia a la escritura de artículos o libros, desarrollo de conocimientos y competencias, asistencia a congresos y seminarios, y estancias científicas; el segundo, denominado cultural, comprendió el aumento de felicidad y condición espiritual de la persona, sentido de tranquilidad y pensamiento sólido respecto a la familia y a la vida profesional, y flexibilidad para adaptarse a nuevas culturas; el tercero, nombrado creación de capacidad científica, mostró el aumento de la capacidad de la persona para la creatividad y la innovación, interés en nuevos temas y líneas de investigación, mejora continua en su calidad de enseñanza en el aula, y la posibilidad de desarrollarse en universidades extranjeras; y el cuarto, llamado motivaciones personales, reveló el aumento del estatus social de la persona y la oportunidad de cooperar con organizaciones internacionales.

Combinando estos estudios, se puede establecer que los beneficios individuales son: a) agente de rejuvenecimiento y renovación, b) actualización profesional y docente, y c) redes profesionales.

\section{Beneficios institucionales}

Zahorski (1994) identificó ocho beneficios: a) mayor eficacia, versatilidad y productividad de la facultad, lo cual incluye la mejora de la enseñanza, incorporación de nuevos cursos, generación de nuevas ideas de investigación; b) fortalecimiento de programas institucionales, por agregar valor a los nuevos programas; c) mejora del ambiente de aprendizaje, incorporando conocimiento de vanguardia; d) mejora de la moral; e) mayor lealtad a la institución, acompañada de compensación financiera por parte de la institución; f) mayor reclutamiento y retención del profesorado, dado que una institución con sabático es más atractiva; g) mejora el clima intelectual, porque en cuanto más actualizado y especializado es el profesorado en su disciplina, el clima intelectual es más dinámico, y h) mayor reputación académica de la institución, por la cantidad de publicaciones.

Sima (2000), en un análisis de la información de los ocho beneficios institucionales planteados por Zahorski en conjunto con las conclusiones del estudio de Sima con Denton realizado en 1995, establece que el sabático facilita el desarrollo y productividad de la facultad; por lo que concluye que los beneficios institucionales son a) aumento de la productividad, b) mejores programas, c) fortalecimiento del clima intelectual, y d) mayor reputación académica.

Carr y Tang (2005) en su estudio mencionan que el efecto positivo del sabático es la capacidad que proporciona a las organizaciones para reducir costos y preservar su inversión en el personal, para que el capital humano esté en su lugar cuando la economía reanude su crecimiento; además, existen otros beneficios: a) método de mantenimiento de la fe entre una 
http://doi.org/10.15359/ree.24-3.4

empresa y su personal cuyas habilidades no son demanda inmediata, pero podrían ser en una fecha posterior, b) incentivo para quienes buscan una flexibilidad en el lugar de trabajo y c) forma para que las empresas ejerzan sus sistemas de controles y balances.

De los cinco componentes examinados en el estudio realizado por Iravani (2011) a 120 miembros de la facultad de la Universidad de Teherán, uno de ellos comprendió la parte institucional. Este componente denominado productividad institucional reveló que el sabático impacta en la internacionalización de la universidad y crea una oportunidad para generar ingresos en el país extranjero donde la persona realiza el sabático.

En el trabajo de tesis de McDearmid (2014), se investigó los resultados a largo plazo que proporciona el sabático, utilizando la revisión sistemática de diez estudios relacionados con la efectividad organizacional y el impacto en el bienestar de personas empleadas; los principales hallazgos de la investigación sustentan que, desde el punto de vista de la organización, el sabático genera buenos rendimientos, como la mejora en sus resultados de producción y la revitalización de la fuerza laboral; incluso, el sabático se puede considerar como una inversión en el recurso más valioso de la organización -el personal empleado-.

En resumen, los beneficios institucionales se pueden agrupar en: a) mayor productividad y eficacia en los programas institucionales, b) mayor lealtad a la institución con diversas compensaciones institucionales, c) posicionamiento institucional y e) fortalecimiento del clima organizacional.

\section{El periodo sabático en Latinoamérica}

En la Tabla 1 se presenta un análisis comparativo de algunas instituciones de educación superior de Latinoamérica que tienen implementado un sabático. En Argentina, la Universidad de Buenos Aires (UBA), la Universidad Nacional de La Plata (UNLP); en Brasil, la Universidad de São Paulo (USP); en Chile, la Pontifica Universidad Católica de Chile (UC), la Universidad de Santiago de Chile (USACH) y la Universidad de Concepción (UDEC); en Colombia, la Universidad Nacional de Colombia (UNAL), la Universidad de los Andes (Uniandes) y la Pontifica Universidad Javeriana (Javeriana); en Costa Rica, la Universidad de Costa Rica (UCR) y la Universidad Nacional de Costa Rica (UNA); en Ecuador, la Universidad San Francisco de Quito (USFQ) y la Pontifica Universidad Católica del Ecuador (PUCE); en Perú, la Pontifica Universidad Católica del Perú (PUCP), la Universidad Nacional Mayor de San Marcos (UNMSM) y la Universidad Peruana Cayetano Heredia (UPCH); en Puerto Rico, la Universidad de Puerto Rico (UPR); en Uruguay, la Universidad de la República (UdelaR); en Venezuela, la Universidad Católica Andrés Bello (UCAB), la Universidad Central de Venezuela (UCV), la Universidad Simón Bolívar (USB) y la Universidad del Zulia (LUZ); finalmente, en México, la UNAM, el IPN, el TecNM y el organismo Servicios Educativos Integrados al Estado de México (SEIEM). 
http://doi.org/10.15359/ree.24-3.4

http://www.una.ac.cr/educare

educare@una.cr

Tabla 1: Análisis de los periodos sabáticos para el profesorado en instituciones de Latinoamérica

\begin{tabular}{|c|c|c|c|c|c|c|c|c|c|c|c|c|c|c|}
\hline \multirow[b]{2}{*}{ Institución } & \multicolumn{2}{|c|}{ Tiempo } & \multicolumn{3}{|c|}{ Investigación } & \multicolumn{2}{|c|}{ Estudios } & \multicolumn{3}{|c|}{$\begin{array}{c}\text { Superación académica o } \\
\text { desarrollo profesional }\end{array}$} & \multicolumn{2}{|c|}{ Institucional } & \multicolumn{2}{|c|}{ Prestación } \\
\hline & 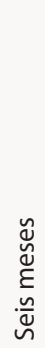 & 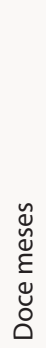 & 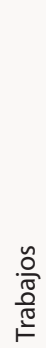 & 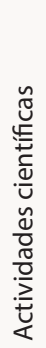 & 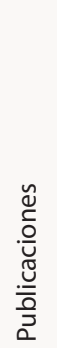 & 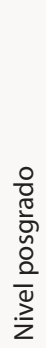 & 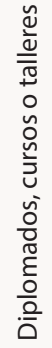 & 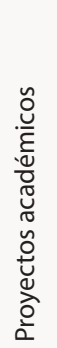 & 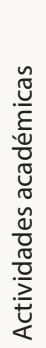 & 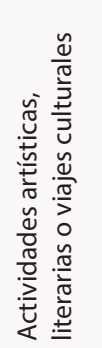 & 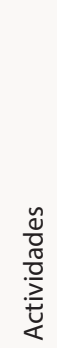 & 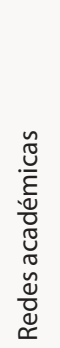 & 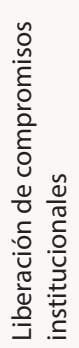 & 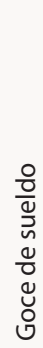 \\
\hline UBA & & $x$ & $x$ & $x$ & $x$ & $\mathrm{x}$ & & & & & & & $\mathrm{x}$ & $x$ \\
\hline UNLP & & $x$ & & $x$ & & & & & $x$ & & & & & $x$ \\
\hline USP & $x$ & $x$ & & $x$ & & & & & & & & & $x$ & \\
\hline UC & $x$ & $x$ & & $x$ & & & & & & & & & $x$ & $x$ \\
\hline USACH & & $x$ & & $x$ & & & & & $x$ & & $x$ & & $x$ & $\mathrm{X}$ \\
\hline UDEC & $x$ & & $x$ & $x$ & & & & & & & & & & $x$ \\
\hline UNAL & $x$ & $x$ & & & & & & $x$ & & & & & $x$ & \\
\hline Uniandes & $x$ & & & & & & & $x$ & & & & & $x$ & $x$ \\
\hline Javeriana & $x$ & & $x$ & & & & & & & & & & $x$ & $x$ \\
\hline UCR & $x$ & $x$ & & & & & & & $x$ & & & & $x$ & $x$ \\
\hline UNA & & $x$ & & & & & & & $x$ & & $x$ & & $x$ & $x$ \\
\hline USFQ & & $x$ & & $x$ & & & & $x$ & $x$ & & & $x$ & & $x$ \\
\hline PUCE & & $x$ & & & $x$ & & & & $x$ & & & $x$ & $x$ & $x$ \\
\hline $\begin{array}{l}\text { PUCP } \\
\text { UNMSM } \\
\text { UPCH }\end{array}$ & & $x$ & & $x$ & $x$ & & & & & & & & & $x$ \\
\hline UPR & $x$ & $x$ & & & & $x$ & & & & $x$ & & & & $x$ \\
\hline UdelaR & & $x$ & & & & $x$ & $x$ & & $x$ & & & & & $x$ \\
\hline UCAB & $x$ & $x$ & & & & & & & $x$ & & $x$ & & $x$ & $x$ \\
\hline UVC & & $x$ & & & & & & & $x$ & & & & & $x$ \\
\hline USB & & $x$ & & $x$ & & & & & $x$ & & & & $x$ & $x$ \\
\hline LUZ & & $x$ & & $x$ & & & & & $x$ & & & & $x$ & $x$ \\
\hline $\begin{array}{l}\text { IPN } \\
\text { UNAM }\end{array}$ & $x$ & $x$ & & & & $x$ & $x$ & & $x$ & & $x$ & & $x$ & $x$ \\
\hline TecNM & $x$ & $x$ & $x$ & $x$ & $x$ & $x$ & $x$ & $x$ & $x$ & & & & $x$ & $x$ \\
\hline SEIEM & $x$ & $x$ & & $x$ & & $x$ & & & $x$ & & & & & $x$ \\
\hline
\end{tabular}

Nota: Elaboración propia, con base en los los documentos normativos, reglamentos, resoluciones, estatutos y leyes del sabático de las instituciones de educación superior mencionadas.

En Colombia, de acuerdo con Bustamante et al. (2004), una de las estrategias para aumentar la productividad científica y la competitividad académica en la Facultad de Ingeniería de la 
http://doi.org/10.15359/ree.24-3.4

Universidad de los Andes es el año sabático, considerado como un mecanismo fundamental para la operación de los programas de doctorado y del desarrollo de actividades de maestría. Vargas Acosta (2016) explica que el distrito de Bogotá, a través de la Secretaría de Educación del Distrito, impulsa el año sabático como una política de incentivos que reconoce a las personas docentes y líderes en la transformación educativa, insertándolas en la red de innovación del distrito, para realizar trabajo conjunto donde compartan conocimientos y experiencia.

En Perú, Ruiz Pérez (2012) plantea que el profesorado de educación básica, a través de una petición formal sobre el derecho del año sabático, genere una legislación o reglamentación que beneficie al profesorado y constituya un factor determinante para favorecer el desarrollo de la educación peruana.

En Venezuela, Pereira de Homes y Ochoa Henríquez (2002) realizaron un análisis de las políticas de formación para el relevo y el perfeccionamiento académico en la Universidad del Zulia, en el cual se considera el año sabático como una estrategia utilizada para actualizar y perfeccionar a su personal académico. En esta política se tienen dos limitaciones: la universidad no elabora planes de formación para el profesorado beneficiado y el profesorado beneficiado debe buscar la cooperación de otro profesorado o cuerpo colegiado de investigación, que se comprometa con su carga académica.

En México, Abascal Gaytán y Abascal Gaytán (2016) realizaron una investigación documental y de campo de la operación del año sabático en la Escuela Superior de Turismo del IPN y encontraron una inconsistencia entre la normativa del sabático y el modelo del IPN; además, explican cómo la falta de retroalimentación de la experiencia del personal docente beneficiado, el poco interés en el seguimiento del personal que preside las academias en los trabajos y productos del personal docente, y la poca difusión a la comunidad del plantel de los productos son elementos que limitan los beneficios a la comunidad estudiantil y al profesorado. De acuerdo con Rivera Mendoza et al. (2009), el género femenino, en el organismo de Servicios Educativos Integrados al Estado de México, tiene una gran participación en los procesos de formación académica a través del sabático, durante los años de 2004-2007: la mujer tuvo una participación del $62 \%$ del total de las 262 personas beneficiadas, en las temáticas de los procesos de enseñanza-aprendizaje, en gestión educativa y en agentes educativos.

Martín-Sempere et al. (1999), en su estudio de movilidad del profesorado latinoamericano a España, a través del sabático entre los años de 1984 y 1994, explican que, de un total de 326 personas recibidas en España, los países de Argentina y México representaron el 64.72\% del profesorado, 116 y 95 respectivamente, quienes obtuvieron una productividad de 290 publicaciones en revistas del Science Citation Index. Por otro lado, de acuerdo con Arribas Urrutia (2007), el sabático en el sector empresarial se entiende como un elemento configurador de flexibilidad que permite, al personal, la posibilidad de disponer de un tiempo fuera de la empresa con remuneración salarial, el cual no es del 100\%. En el trabajo de Domínguez 
http://doi.org/10.15359/ree.24-3.4

http://www.una.ac.cr/educare

educare@una.cr

Martínez et al. (2011) se menciona que el sabático en la empresa se implementa como una medida potencial para lograr una disminución de los costes laborales, es de carácter voluntario por parte del personal y se considera de naturaleza transitoria para la empresa; como ejemplo, Cervantes (2005) explica que el sabático en la empresa IBM se considera como una opción de flexibilidad en el trabajo, donde el personal atiende iniciativas de carácter propio durante un año, no se presenta a trabajar en IBM y percibe un $25 \%$ de su salario fijo, con ello IBM pretende que el sabático sea un instrumento de retención de talento, así como un elemento para la motivación y la calidad de vida del personal de la empresa.

\section{La formación académica del profesorado del TecNM en el periodo sabático}

De acuerdo con el Decreto que crea el Tecnológico Nacional de México (2014, DECRETO, párr. 2), el TecNM es "un órgano administrativo desconcentrado de la Secretaría de Educación Pública, con autonomía técnica, académica y de gestión", tiene cobertura en todo México y es una de las instituciones de educación superior más grande en Latinoamérica, concentra a 254 instituciones: 122 institutos tecnológicos descentralizados y 132 instituciones federales. En el ciclo escolar 2018-2019, el TecNM, a través de sus institutos, ofreció 1816 programas educativos en todo el país, los cuales atendieron a una comunidad de 608283 estudiantes, con el empleo de una planta docente de 29579 (TecNM, 2018a).

\section{El periodo sabático del TecNM}

El TecNM promueve el sabático para la realización de investigación, estudios formales de nivel posgrado y todas aquellas actividades académicas que coadyuven a la superación académica del profesorado, puede ser de doce o seis meses, y está dirigido al profesorado de los 132 instituciones federales que tienen una plaza de base de tiempo completo; su operación se realiza a través de una convocatoria que se publica de manera semestral.

De acuerdo con el TecNM (2016), el sabático establece siete propósitos: 1) PS1-Investigación, 2) PS2-Estudios de nivel posgrado, 3) PS3-Tesis, 4) PS4-Formación y superación docente, 5) PS5-Elaboración de material y auxiliares didácticos para la enseñanza, 6) PS6-Estadías y 7) PS7Proyectos empresariales. En la Tabla 2 se exponen los propósitos, programas y su descripción de los cuales el profesorado del TecNM puede seleccionar para disfrutar su sabático. En el PS1 se puede optar por tres tipos de programas de investigación (científica, tecnológica y educativa); en el PS5 es posible escoger diez tipos de programas relacionados con la elaboración de materiales didácticos (apuntes, libro, reactivos de evaluación, casos de estudio, metodologías basadas en proyectos/problemas, proyectos integradores, y desarrollo de software/multimedios/ambientes virtuales); y en los PS2, PS3, PS4, PS6 y PS7 no se tienen programas que el profesorado pueda elegir, por lo que sólo se proporciona la descripción de los propósitos. 
Tabla 2: Propósitos y programas del periodo sabático del TecNM

\begin{tabular}{|c|c|c|}
\hline \multirow{2}{*}{ No. } & \multicolumn{2}{|r|}{ Descripción del propósito } \\
\hline & Programa & Definición \\
\hline \multirow{3}{*}{ PS1 } & $\begin{array}{l}\text { Investigación } \\
\text { científica (PS1A) }\end{array}$ & $\begin{array}{l}\text { Se refiere a la generación del conocimiento de las ciencias para el planteamiento y solución de problemas de } \\
\text { contexto. }\end{array}$ \\
\hline & $\begin{array}{l}\text { Investigación } \\
\text { tecnológica (PS1B) }\end{array}$ & $\begin{array}{l}\text { Se refiere al diseño, desarrollo y aplicación de tecnologías, hardware y software, es decir, desarrollo de sistemas } \\
\text { y plataformas, así como la producción de programas de cómputo. }\end{array}$ \\
\hline & $\begin{array}{l}\text { Proyecto de } \\
\text { investigación } \\
\text { educativa (PS1C) }\end{array}$ & $\begin{array}{l}\text { Se refiere a la aplicación del conocimiento en un proyecto estratégico para el diagnóstico e interpretación de } \\
\text { los diversos escenarios educativos que se presentan en la vida institucional. }\end{array}$ \\
\hline PS2 & \multicolumn{2}{|c|}{$\begin{array}{l}\text { Se refiere a todos los estudios formales de tiempo completo en modalidad escolarizada, opción presencial, que se realizan en México o en el } \\
\text { extranjero para la obtención de un grado académico de nivel posgrado (los estudios pueden ser de especialización, maestría y doctorado). }\end{array}$} \\
\hline PS3 & \multicolumn{2}{|c|}{$\begin{array}{l}\text { Se refiere al trabajo de investigación final de un nivel de estudios de posgrado, el cual es el resultado del proceso de formación y } \\
\text { desarrollo de actividades de investigación orientadas a las áreas científica y tecnológica, durante la estancia en la institución. }\end{array}$} \\
\hline PS4 & \multicolumn{2}{|c|}{$\begin{array}{l}\text { Se refiere a la realización de estudios con una orientación a desarrollo de competencias profesionales y laborales de la profesión que } \\
\text { fortalecen la docencia, es decir, la capacitación y acreditación de cursos, talleres, seminarios, diplomados o certificaciones. }\end{array}$} \\
\hline \multirow{10}{*}{ PS5 } & $\begin{array}{l}\text { Apuntes: manual de } \\
\text { prácticas (PS5A) }\end{array}$ & $\begin{array}{l}\text { Se refiere al trabajo académico que se realiza para el desarrollo de competencias profesionales en la } \\
\text { comunidad estudiantil, el cual es el resultado del desarrollo de actividades académicas implementadas en el } \\
\text { aula durante uno o varios cursos de las asignaturas. }\end{array}$ \\
\hline & Libro de texto (PS5B) & $\begin{array}{l}\text { Hace referencia a una obra impresa, producto de un texto diseñado para promover las competencias profesionales en } \\
\text { la comunidad estudiantil y preferentemente orientado a las asignaturas de los programas educativos. }\end{array}$ \\
\hline & $\begin{array}{l}\text { Elaboración de } \\
\text { reactivos de } \\
\text { evaluación (PS5C) }\end{array}$ & $\begin{array}{l}\text { Hace referencia al diseño y elaboración de un problema de contexto en un área específica, para que sea } \\
\text { respondido y desarrollado por una persona con la finalidad de medir a través de una rúbrica, el dominio de } \\
\text { sus competencias. }\end{array}$ \\
\hline & $\begin{array}{l}\text { Casos de estudio } \\
\text { (PS5D) }\end{array}$ & $\begin{array}{l}\text { Se refiere a la estrategia de investigación en la que se describen varias argumentaciones e hipótesis de cir- } \\
\text { cunstancias o acontecimientos que se han presentado en la vida real en diferentes contextos, con la finalidad } \\
\text { de que la comunidad estudiantil genere diversos planteamientos y soluciones al caso. }\end{array}$ \\
\hline & $\begin{array}{l}\text { Aprendizaje basado } \\
\text { en problemas (PS5E) }\end{array}$ & $\begin{array}{l}\text { Se refiere a la estrategia en la que se plantean varios hechos y datos de una situación en un escenario, con la finalidad } \\
\text { de que la comunidad estudiantil analice, investigue y plantee argumentaciones que sirvan como posibles soluciones. }\end{array}$ \\
\hline & $\begin{array}{l}\text { Aprendizaje basado } \\
\text { en proyectos (PS5F) }\end{array}$ & $\begin{array}{l}\text { Se refiere a la metodología en la que se plantea un proyecto relacionado con el contexto de la profesión, con } \\
\text { la finalidad de que la comunidad estudiantil formule la planeación y el desarrollo del proyecto para el logro } \\
\text { de las competencias profesionales. }\end{array}$ \\
\hline & $\begin{array}{l}\text { Proyectos } \\
\text { integradores (PS5G) }\end{array}$ & $\begin{array}{l}\text { Se refiere a la estrategia en la que se plantea un proyecto real a la institución para atender una problemática real de } \\
\text { su entorno, con la finalidad de que la comunidad estudiantil de diferentes profesiones integre una solución con sus } \\
\text { competencias profesionales y desarrollen el proyecto para dar respuesta a la problemática real. }\end{array}$ \\
\hline & $\begin{array}{l}\text { Software educativo } \\
\text { (PS5H) }\end{array}$ & $\begin{array}{l}\text { Se refiere a las aplicaciones y programas realizados por un conjunto de herramientas informáticas, que } \\
\text { se diseñan con la finalidad de proporcionar materiales pedagógicos para fortalecer el desarrollo de las } \\
\text { competencias en la comunidad estudiantil. }\end{array}$ \\
\hline & Multimedios (PS5I) & $\begin{array}{l}\text { Hace referencia al conjunto de materiales didácticos para el desarrollo de las competencias profesionales de } \\
\text { la comunidad estudiantil, que son resultado de la integración lógica y ordenada principalmente de textos, } \\
\text { gráficos, imágenes, animaciones, videos y sonidos. }\end{array}$ \\
\hline & $\begin{array}{l}\text { Ambiente virtual } \\
\text { (PS5J) }\end{array}$ & $\begin{array}{l}\text { Hace referencia al sistema virtual, en el cual interactúan a distancia la comunidad estudiantil y el profesorado } \\
\text { para el desarrollo de competencias, dicho sistema es el resultado de integrar herramientas, tecnologías, } \\
\text { plataformas, medios digitales, y dispositivos electrónicos. }\end{array}$ \\
\hline PS6 & \multicolumn{2}{|c|}{$\begin{array}{l}\text { Hace referencia al trabajo que desarrolla la comunidad docente en el sector industrial o centros de investigación, el cual tiene como } \\
\text { finalidad su formación, capacitación y actualización profesional. }\end{array}$} \\
\hline PS7 & \multicolumn{2}{|c|}{$\begin{array}{l}\text { Se refiere al trabajo que realiza el profesorado mediante un proyecto para una empresa, con la finalidad de que desarrolle sus } \\
\text { habilidades de la profesión, la innovación y el emprendimiento. }\end{array}$} \\
\hline
\end{tabular}

Nota: Elaboración propia, con base en el análisis de la información de los programas establecidos por el TecNM (2016). 
http://doi.org/10.15359/ree.24-3.4

http://www.una.ac.cr/educare

educare@una.cr

\section{Estrategia metodológica y análisis de resultados}

El Modelo Educativo del TecNM impulsa la formación docente y actualización profesional, así como la formación de capital humano para la investigación (DGEST, 2012), mientras que el Reglamento Interior de Trabajo del Personal Docente de los Institutos Tecnológicos promueve el sabático para la realización de investigación, estudios formales de nivel posgrado y todas aquellas actividades académicas que coadyuven a la superación a académica del profesorado (Secretaría de Educación Pública [SEP], 1982); por lo anterior, el periodo sabático del TecNM se encuentra en la base legal de la institución.

Con el referente anterior, en esta sección se describen las acciones y actividades que se realizaron en esta investigación, así como la discusión de los hallazgos detectados.

\section{Metodología}

\section{Tipo de investigación}

De acuerdo con la clasificación proporcionada por Hernández Sampieri et al. (2014), se realizó una investigación no experimental de corte cuantitativo, con diseño transversal y descriptivo documental del profesorado de tiempo completo que presentó solicitudes al periodo sabático del TecNM en los años académicos 2012-2018. La investigación permitió medir las variables de: sexo, edad y distribución geográfica (en grandes grupos); lugar de estancia (México vs. extranjero); tipo de institución (empresa, universidad o centro de investigación); distribución geográfica en el extranjero (países); y los programas académicos (investigación, estudios de nivel posgrado, tesis, formación y superación docente, elaboración de material y auxiliares didácticos para la enseñanza, estadías, y proyectos empresariales).

\section{Instrumentos}

Se utilizaron las fichas entregadas por los institutos: revisión técnica realizada por las academias, solicitud del interesado, proyecto académico y los dictámenes. Toda esta documentación está validada y es utilizada por el TecNM para verificar el cumplimiento del sabático (SEP, 2018). Estos instrumentos están destinados a recolectar la información formal que entregan los institutos adscritos al TecNM, relacionada con los datos de la persona participante, el nombre del programa académico, el tiempo autorizado, la descripción del proyecto, la evaluación de reporte entregado y los resultados obtenidos. Los archivos de las fichas actualmente están en resguardo de la Dirección de Docencia e Innovación Educativa del TecNM, ubicada en la Dirección General en la Ciudad de México. 


\section{Procedimiento}

La investigación se elaboró en cinco fases: en la primera se realizó un análisis comparativo de la bibliografía científica, documentos normativos, reglamentos, resoluciones, estatutos y leyes referentes al sabático en diversas instituciones; en la segunda se identificaron las variables a analizar en las aplicaciones al periodo sabático que realizó el profesorado del TecNM en los años académicos 2012-2018; en la tercera se llevó a cabo una revisión exhaustiva de los documentos consultados para obtener los datos de las variables a analizar; en la cuarta se sistematizó la información recolectada, integrándola y clasificándola en catálogos tipo tabla elaborados en formato Office Excel; y, por último, se realizó el análisis estadístico descriptivo, el cual generó los resultados, tablas y figuras presentadas en este artículo.

\section{Participantes}

El universo del estudio estuvo constituido por un profesorado de tiempo completo de 10264 (70.4\% hombres y 29.6\% mujeres), quienes pertenecen a 132 instituciones federales; lo anterior debido a que el sabático del TecNM está dirigido al profesorado que tiene una plaza de base de tiempo completo de las instituciones federales.

El análisis de la producción del sabático se realizó para las aplicaciones de los años académicos 2012-2018, al considerar que el último año solo se tienen resultados de la primera convocatoria realizada durante el primer semestre. Para efectos del estudio, se empleó una muestra de $n=3,179$ personas de la planta docente que presentaron solicitudes al periodo sabático, las cuales fueron aprobadas durante el tiempo en estudio; lo anterior representa el 30.97\% del total del profesorado con plaza base de tiempo completo, del cual sólo 2665 (83.83\%) han concluido su sabático, debido a que el profesorado de las convocatorias del segundo semestre 2017 y primer semestre 2018 se encuentran en proceso de conclusión. De los 2665 se encontró que solo 2357 tienen el estado de liberado, es decir, cuentan con toda la documentación formal que soporta la terminación del periodo sabático, mientras que las 308 personas faltantes, aún no tienen la liberación, debido a que no han entregado su informe final. Con base en lo anterior, se deduce que el sabático del TecNM en los años académicos analizados tiene una eficiencia terminal del $88.44 \%$.

\section{Consideraciones éticas}

Debido a que la fuente principal de documentación e información para realizar la presente investigación proviene de Tecnológico Nacional de México, se solicitó permiso a través de la Dirección de Docencia e Innovación Educativa del TecNM para su utilización con fines de identificación, estadística e investigación, con el compromiso de guardar la confidencialidad y dar cumplimiento a los lineamientos éticos de la institución sobre los datos de las personas que aplicaron al sabático, es decir, en este artículo no aparecen datos de personas. Se trata de un estudio original que no ha sido publicado previamente. 
http://doi.org/10.15359/ree.24-3.4

http://www.una.ac.cr/educare

educare@una.cr

\section{Resultados}

En la Figura 1 se observa la participación por año de la variable sexo del profesorado beneficiado con un sabático-durante los años académicos 2012-2018, las $n=3179$ personas que constituyen la muestra se distribuyen en $65.78 \%$ hombres y $34.22 \%$ mujeres, esto demuestra que la participación de la mujer en el sabático es amplia en el interior de las instituciones que pertenecen al TecNM. También se aprecia que, de manera anual, se tiene una participación de un $64.09 \%$ al $67.86 \%$ de hombres, y del $32.14 \%$ al $35.91 \%$ de mujeres, es decir, en promedio se tiene un beneficio anual de 498 personas, de las cuales 327 (65.66\%) son hombres y 171 (34.34\%) mujeres (se excluye el año 2018, debido a que sólo se refiere a un semestre y no al año completo). Por lo anterior, se puede establecer que el TecNM ha beneficiado anualmente a un $4.85 \%$ de personas para el periodo sabático, respecto las 10264 personas de su planta docente total.

Figura 1: Distribución del profesorado de sabático del TecNM durante los años académicos 2012-2018

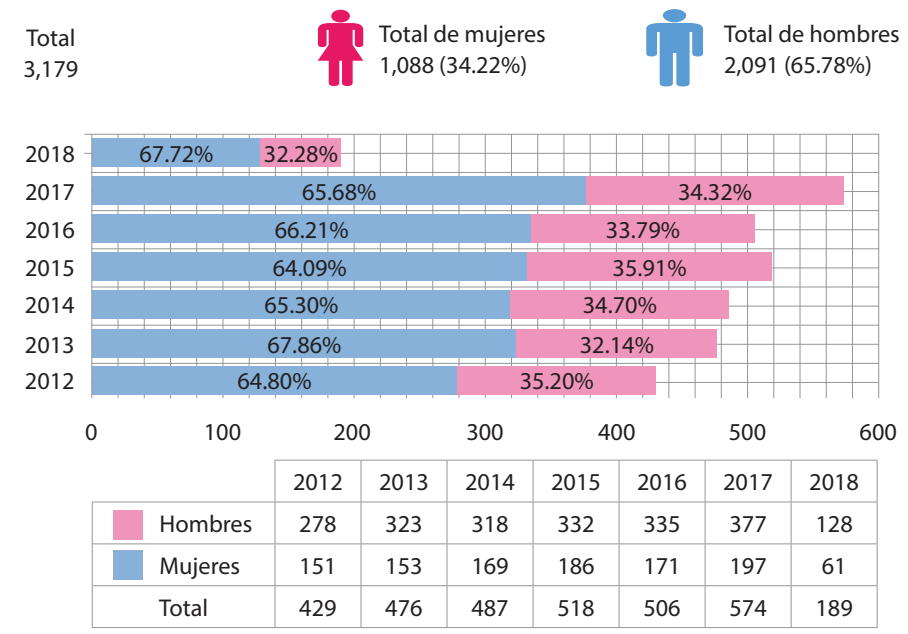

Nota: Elaboración propia, con base a la muestra de 3,179 personas docentes que aplicaron para el periodo sabático durante los años académicos 2012-2018.

En la Tabla 3 se observa que el Estado de la República Mexicana que más sabáticos ha otorgado es Chihuahua con un 10.13\% (322) respecto a la muestra $n=3$ 179, también tiene la mayor participación de las mujeres con 134 que equivale a un 4.22\% y de hombres con 188 que equivale a un 5.91\%. Los Estados de Chihuahua, Michoacán, Veracruz, Tamaulipas, Sonora, Sinaloa, Durango, Baja California, Coahuila y Yucatán tienen el $60.27 \%$ de participación del profesorado en régimen sabático de todo el país. Por otro lado, con base en las zonas, se confirma que la mayor participación es en el norte de México (zonas noreste-y noroeste). La noreste tiene una mayor participación del país con un total de 964 personas (344 mujeres y 620 hombres) que corresponde al 30.32\% del total de la muestra ( $n=3179)$. 
Tabla 3: Distribución del profesorado del periodo sabático del TecNM por Estado de la República Mexicana

\begin{tabular}{|c|c|c|c|c|c|c|c|}
\hline Zona & $\begin{array}{c}\text { Estado de la República } \\
\text { Mexicana }\end{array}$ & $\begin{array}{l}\text { No. de } \\
\text { planteles }\end{array}$ & $\begin{array}{c}\text { Total } \\
(t)\end{array}$ & $\begin{array}{l}\text { Hombre } \\
(h)\end{array}$ & $\begin{array}{c}\% \\
(h / t)\end{array}$ & $\begin{array}{l}\text { Mujer } \\
(m)\end{array}$ & $\begin{array}{c}\% \\
(m / t) \\
\end{array}$ \\
\hline \multirow{7}{*}{$\begin{array}{l}\text { Noreste } \\
\text { Total=964 } \\
\text { Mujeres=344 } \\
(35.68 \%) \\
\text { Hombres=620 } \\
(64.32 \%)\end{array}$} & Chihuahua & 8 & 322 & 188 & 58.39 & 134 & 41.61 \\
\hline & Tamaulipas & 6 & 200 & 126 & 63 & 74 & 37 \\
\hline & Durango & 3 & 151 & 115 & 76.16 & 36 & 23.84 \\
\hline & Coahuila & 4 & 129 & 87 & 67.44 & 42 & 32.56 \\
\hline & San Luis Potosí & 3 & 68 & 35 & 51.47 & 33 & 48.53 \\
\hline & Nuevo León & 2 & 54 & 35 & 64.81 & 19 & 35.19 \\
\hline & Zacatecas & 1 & 40 & 34 & 85 & 6 & 15 \\
\hline \multirow{7}{*}{$\begin{array}{l}\text { Occidente } \\
\text { Total=678 } \\
\text { Mujeres=194 } \\
(28.61 \%) \\
\text { Hombres=484 } \\
(71.39 \%)\end{array}$} & Michoacán & 6 & 239 & 183 & 76.57 & 56 & 23.43 \\
\hline & Aguascalientes & 3 & 116 & 76 & 65.52 & 40 & 34.48 \\
\hline & Guanajuato & 4 & 92 & 60 & 65.22 & 32 & 34.78 \\
\hline & Nayarit & 4 & 80 & 53 & 66.25 & 27 & 33.75 \\
\hline & Querétaro & 3 & 54 & 34 & 62.96 & 20 & 37.04 \\
\hline & Colima & 1 & 50 & 40 & 80 & 10 & 20 \\
\hline & Jalisco & 3 & 47 & 38 & 80.85 & 9 & 19.15 \\
\hline \multirow{4}{*}{$\begin{array}{l}\text { Noroeste } \\
\text { Total=548 } \\
\text { Mujeres=199 } \\
(36.31 \%) \\
\text { Hombres=349 } \\
(63.6 \%)\end{array}$} & Sonora & 6 & 194 & 124 & 63.92 & 70 & 36.08 \\
\hline & Sinaloa & 4 & 174 & 113 & 64.94 & 61 & 35.06 \\
\hline & Baja California & 3 & 151 & 93 & 61.59 & 58 & 38.41 \\
\hline & Baja California Sur & 1 & 29 & 19 & 65.52 & 10 & 34.48 \\
\hline \multirow{4}{*}{$\begin{array}{l}\text { Sur } \\
\text { Total=495 } \\
\text { Mujeres=183 } \\
(36.97 \%) \\
\text { Hombres=312 } \\
(63.03 \%)\end{array}$} & Veracruz & 7 & 231 & 127 & 54.98 & 104 & 45.02 \\
\hline & Oaxaca & 11 & 108 & 66 & 61.11 & 42 & 38.89 \\
\hline & Guerrero & 6 & 90 & 66 & 73.33 & 24 & 26.67 \\
\hline & Chiapas & 4 & 66 & 53 & 80.30 & 13 & 19.70 \\
\hline \multirow{6}{*}{$\begin{array}{l}\text { Centro } \\
\text { Total=295 } \\
\text { Mujeres=95 } \\
(32.20 \%) \\
\text { Hombres=200 } \\
(67.80 \%)\end{array}$} & Estado de México & 2 & 83 & 47 & 56.63 & 36 & 43.37 \\
\hline & Morelos & 3 & 71 & 54 & 76.06 & 17 & 23.94 \\
\hline & Puebla & 3 & 65 & 46 & 70.77 & 19 & 29.23 \\
\hline & Tlaxcala & 2 & 42 & 36 & 85.71 & 6 & 14.29 \\
\hline & Hidalgo & 3 & 19 & 14 & 73.68 & 5 & 26.32 \\
\hline & Ciudad de México & 12 & 15 & 3 & 20 & 12 & 80 \\
\hline \multirow{4}{*}{$\begin{array}{l}\text { Sureste } \\
\text { Total=199 } \\
\text { Mujeres=73 } \\
(36.68 \%) \\
\text { Hombres=126 } \\
(63.32 \%)\end{array}$} & Yucatán & 4 & 125 & 80 & 64 & 45 & 36 \\
\hline & Quintana Roo & 3 & 44 & 33 & 75 & 11 & 25 \\
\hline & Tabasco & 4 & 23 & 8 & 34.78 & 15 & 65.22 \\
\hline & Campeche & 3 & 7 & 5 & 71.43 & 2 & 28.57 \\
\hline Total & & 132 & 3,179 & 2,091 & 65.78 & 1,088 & 34.22 \\
\hline
\end{tabular}

Nota: Elaboración propia, con base en la muestra de 3179 docentes que aplicaron para el periodo sabático durante los años académicos 2012-2018. 
http://doi.org/10.15359/ree.24-3.4

http://www.una.ac.cr/educare

educare@una.cr

En la Figura 2 se presenta la distribución de las edades de las personas participantes en seis rangos de años de edad: 25-35, 36-46, 47-57, 58-68, 69-79 y 80-82, se aprecia que de las $n=3179$ solicitudes, 1387 personas (43.63\%) corresponde al rango de edad de 47 a 57 años y 1167 personas (36.71\%) corresponden al rango de edad de 58 a 68 años; con base en lo anterior, 2554 personas (80.34\%) del profesorado en régimen sabático del TecNM tienen una edad de 47 a 68 años. De acuerdo con L. Abascal Gaytán y R. P. Abascal Gaytán (2016), esto es un riesgo, debido a que una parte del profesorado que disfruta del sabático al regresar tramita su jubilación, como consecuencia no hay beneficio para las comunidades educativas, ni para la sociedad que aporta recursos para que el profesorado goce de sueldo en el sabático; por otro lado, se tiene el riesgo de una bijubilación del profesorado, "esto es, la persona que al borde de los 50 años de edad tiene una jubilación y puede esperar otra, antes de los 70 años" (Albornoz, 1998, p. 107). Otro aspecto derivado de la gráfica hace suponer que el relevo generacional (personas jóvenes) no tienen mucha contribución en el sabático del TecNM, lo cual nos lleva a pensar que este sector del personal docente no tiene interés en participar o no cumple con los requisitos establecidos por el TecNM.

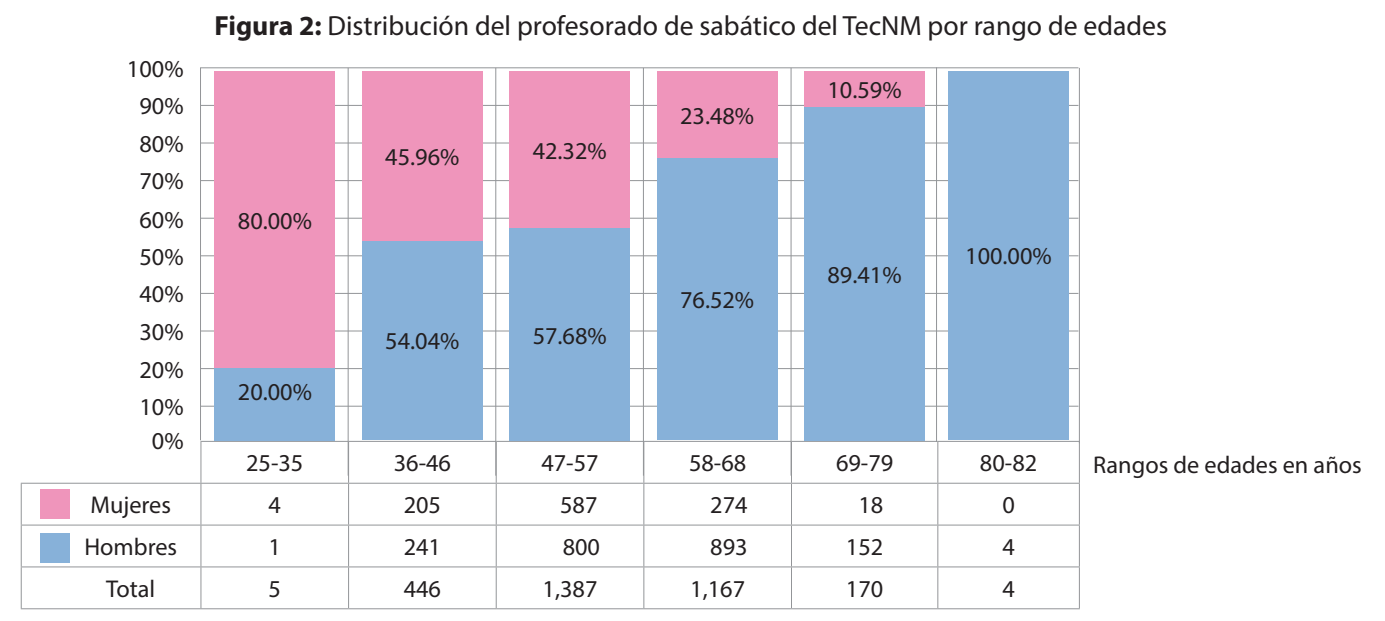

Nota: Elaboración propia, con base en la muestra de 3,179 personas docentes que aplicaron para el periodo sabático durante los años académicos 2012-2018.

En la Tabla 4, se presenta la estadística descriptiva de la edad del profesorado que realizó su sabático durante los años académicos 2012-2018, la edad media es de $55.74 \pm 7.92$ años con un rango de 25 a 82 años, de los cuales la mitad del profesorado tiene una edad menor a los 56 años y se estima que el $50 \%$ tiene una edad entre los 50 y 61 años. Las personas de 60 años son las que más aplicaron para el sabático. La distribución es positiva y platicúrtica, debido a que tiene un valor de sesgo de 0.05 y la curtosis tiene un valor negativo de -0.25 . 
Tabla 4: Estadística descriptiva de la edad del profesorado que aplicó al periodo sabático del TecNM

\begin{tabular}{|c|c|c|}
\hline Media & \multicolumn{2}{|c|}{55.74} \\
\hline Error típico & \multicolumn{2}{|c|}{0.140} \\
\hline Mediana & \multicolumn{2}{|c|}{56} \\
\hline Moda & \multicolumn{2}{|c|}{60} \\
\hline Desviación estándar & \multicolumn{2}{|c|}{7.92} \\
\hline Varianza de la muestra & \multicolumn{2}{|c|}{62.74} \\
\hline Curtosis & \multicolumn{2}{|c|}{-0.25} \\
\hline Coeficiente de asimetría & \multicolumn{2}{|c|}{0.05} \\
\hline Rango & \multicolumn{2}{|c|}{57} \\
\hline Mínimo & \multicolumn{2}{|c|}{25} \\
\hline Máximo & \multicolumn{2}{|c|}{82} \\
\hline Suma & \multicolumn{2}{|c|}{17720} \\
\hline Cuenta & \multicolumn{2}{|c|}{3179} \\
\hline \multirow{3}{*}{ Percentiles } & 25 & 50 \\
\hline & 50 & 56 \\
\hline & 75 & 61 \\
\hline
\end{tabular}

Nota: Elaboración propia, con base en la muestra de 3179 docentes que aplicaron para el periodo sabático durante los años académicos 2012-2018.

En la Figura 3 el 98.68\% (3 137 personas) de la muestra $n=3179$ tiene una preferencia para realizar su sabático en México (65.76\% hombres y 34.24\% mujeres) y sólo $1.32 \%$ (42 personas) de la muestra $n=3179$ tiene una movilidad al extranjero (66.67\% hombres y $33.33 \%$ mujeres). De los 2091 hombres de la muestra $n=3$ 179, el 98.66\% (2 063) realizó su sabático en México y el 1.34\% (28) en el extranjero; mientras que las 1088 mujeres de la muestra $n=3$ 179, el 98.71\% ( 1 074) lo realizó en México y el 1.29 \% (14) en el extranjero; por lo anterior se confirma que el TecNM tiene poca movilidad de profesorado al extranjero en el periodo sabático. 
http://doi.org/10.15359/ree.24-3.4

http://www.una.ac.cr/educare

educare@una.cr

Figura 3: Distribución del profesorado de sabático del TecNM por lugar de estancia
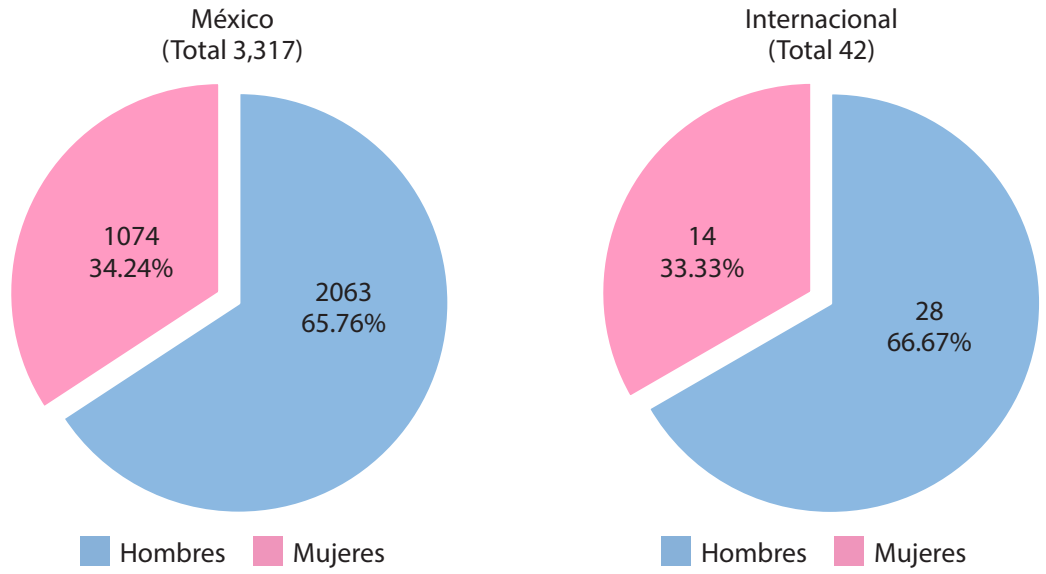

Nota: Elaboración propia, con base en la muestra de 3,179 personas docentes que aplicaron para el periodo sabático durante los años académicos 2012-2018.

En la Tabla 5 se observa el tipo de institución que selecciona el profesorado para realizar el sabático, tanto en México como en el extranjero, solo para el caso de México se consideró al TecNM, distinguiendo a aquellas personas que realizan su sabático en su misma institución (propio) u otra institución diferente que pertenece al TecNM (otro), mientras que la clasificación que se utilizó tanto para nacional como internacional fue a) Empresa, b) Universidad, como cualquier institución de educación superior en el extranjero y en México, diferente a las del TecNM, y c) Centro de investigación para el caso de México diferente a los del TecNM. Es relevante mencionar que, de las 3137 personas participantes en el sabático en México respecto a la muestra $n=3$ 179, el 85.91\% (2 695) prefiere su propia institución, con lo cual limita los beneficios de movilidad del profesorado, expansión de la red profesional con nuevos cuerpos colegiados profesionales de otras instituciones, así como el mejoramiento de la enseñanza, a través de las experiencias obtenidas en otras costumbres, ideologías y cultura de otros países; $y$, en segundo lugar de demanda, el 9.63\% (302) perfeccionan y actualizan sus competencias en el sector empresarial. En el extranjero se observa que el profesorado tiene movilidad principalmente al sector empresarial, de las 42 personas, el $83.33 \%$ (35) realiza su sabático en una empresa. De lo anterior se tiene que el $98.68 \%$ del total de la muestra $(n=3179)$ realiza su sabático en México, mientras que en la Figura 4 se observa el otro $1.32 \%$ que se encuentra distribuido en países del continente americano (EUA, Canadá, Chile, Costa Rica y Cuba), del continente europeo (España, Francia, Reino Unido, Alemania y Holanda) y uno del continente asiático (China); los de mayor demanda son EUA y España, con $35.71 \%$ (15) y $23.81 \%$ (10) solicitudes, respectivamente. 
http://doi.org/10.15359/ree.24-3.4

http://www.una.ac.cr/educare

educare@una.cr

Tabla 5: Distribución del profesorado del periodo sabático del TecNM por tipo de institución, donde realizaron su estancia en el Extranjero y en México

\begin{tabular}{|c|c|c|c|c|c|c|c|c|c|c|c|}
\hline \multirow{2}{*}{\multicolumn{2}{|c|}{ Institución }} & \multicolumn{5}{|c|}{ Extranjero } & \multicolumn{5}{|c|}{ México } \\
\hline & & 焉 & 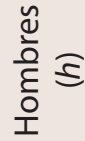 & 。 & 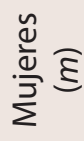 & $\circ{ }^{\circ} \underline{\Sigma}$ & $\stackrel{\bar{\pi}}{0} \equiv$ & 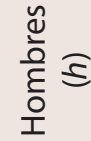 & o & 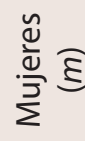 & $\circ \stackrel{\equiv}{\xi}$ \\
\hline \multicolumn{2}{|c|}{ Empresa } & 35 & 25 & 71.43 & 10 & 28.57 & 302 & 210 & 69.54 & 92 & 30.46 \\
\hline \multicolumn{2}{|c|}{ Universidad } & 5 & 3 & 60 & 2 & 40 & 91 & 57 & 62.64 & 34 & 37.36 \\
\hline \multicolumn{2}{|c|}{ Centro de investigación } & 2 & 0 & 0 & 2 & 100 & 26 & 21 & 80.77 & 5 & 19.23 \\
\hline \multirow{2}{*}{ TecNM } & Propio & \multirow{2}{*}{\multicolumn{5}{|c|}{ No aplica }} & 2,695 & 1,762 & 65.38 & 933 & 34.62 \\
\hline & Otro & & & & & & 23 & 13 & 56.52 & 10 & 43.48 \\
\hline \multicolumn{2}{|l|}{ Total } & 42 & 28 & 66.67 & 14 & 33.33 & 3,137 & 2,063 & 65.76 & 1,074 & 34.24 \\
\hline
\end{tabular}

Nota: Elaboración propia, con base en la muestra de 3179 docentes que aplicaron para el periodo sabático durante los años académicos 2012-2018.

Figura 4: Distribución del profesorado de sabático del TecNM en el extranjero

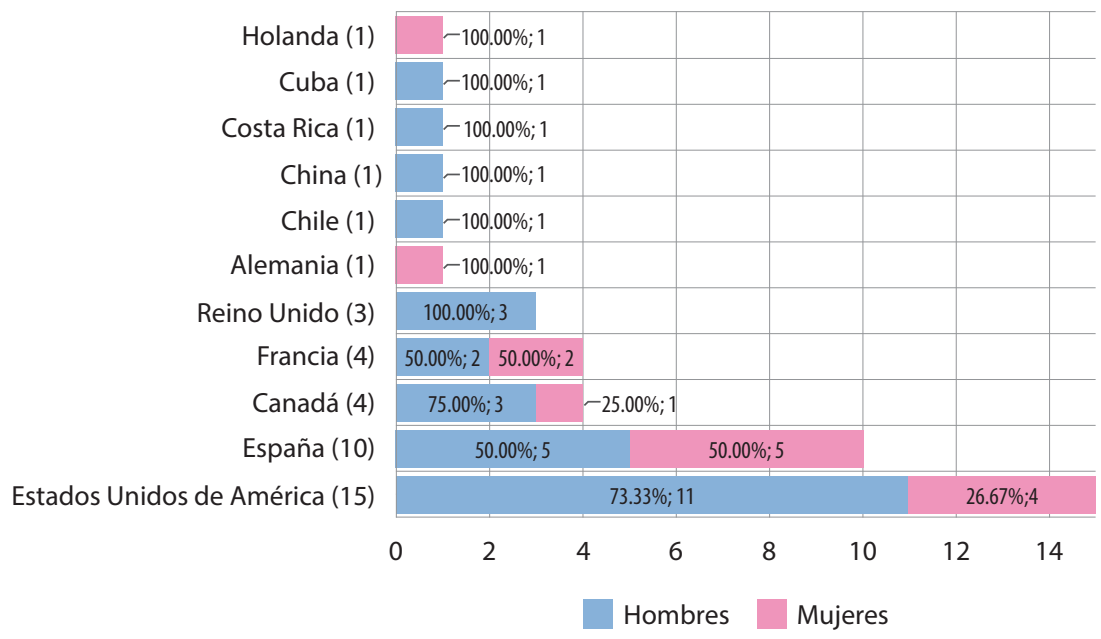

Nota: Elaboración propia, con base en las 42 personas docentes que aplicaron para el periodo sabático a una estancia fuera de México, durante los años académicos 2012-2018. 
http://doi.org/10.15359/ree.24-3.4

http://www.una.ac.cr/educare

educare@una.cr

En la Tabla 6 se tiene la distribución por programa que desarrolla el profesorado en régimen de sabático. Se observa que el de mayor demanda es el PS5 que tiene el $77.76 \%$ (2 472), de los cuales la mayoría se encuentra concentrado en dos programas: el PS5A con 1204 personas y el PS5B con 1084 personas. El otro propósito que más aporta es el PS6 con un 11.61\% (369), aunque éste se encuentra como el segundo propósito de mayor demanda, es claro que existe una gran diferencia con respecto al PS5. El otro propósito solicitado por el profesorado es el PS1, que tiene una contribución del 7.80\% (248), de los cuales 178 prefieren el PS1A, 51 realizan el PS1B, y 19 seleccionaron el PS1C. Los otros cuatro propósitos, PS2, PS3, PS4 y PS7, sólo representan el $2.83 \%$ (90) del total de la muestra ( $n=3$ 179). Por lo anterior, el TecNM en su sabático contempla todos los propósitos que se mencionaron en la revisión de bibliográfica y se observa una falta de equilibrio en la participación del profesorado en sus diversos programas. Por ejemplo, aunque solo 6 personas del sabático del TecNM han participado en el PS5J, no se ha explorado la manera de internacionalizar los sabáticos a través de los sabáticos virtuales que, en términos de Easteal y Westmarland (2010), requieren identificar una institución anfitriona, articular el objetivo del sabático, explorar los software y tecnologías para lograr los objetivos vía ciber-espacio e implementar el networking para su realización sin ausentarse del lugar de origen del profesorado.

Tabla 6: Distribución del profesorado del periodo sabático del TecNM por programa desarrollado

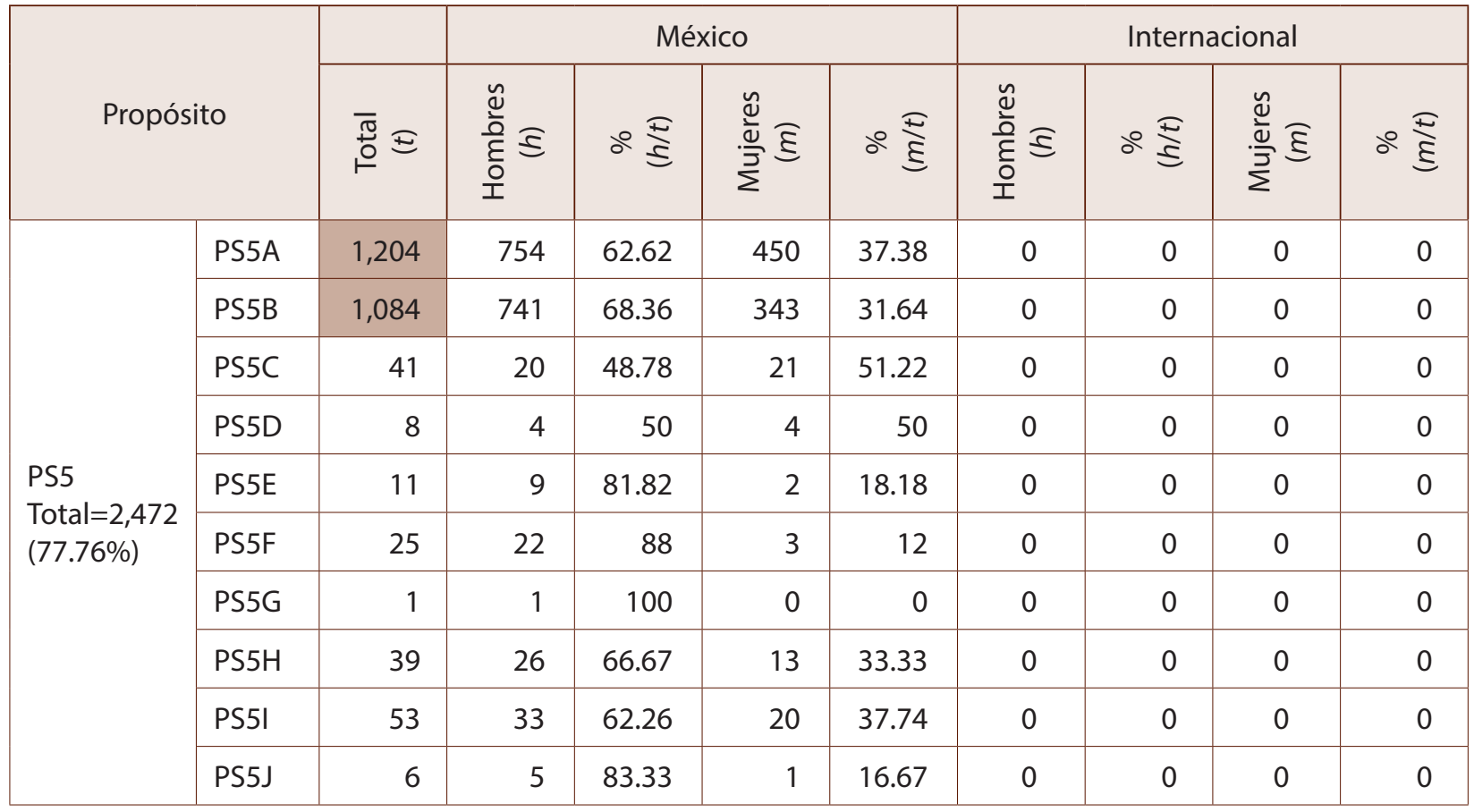

continúa 


\begin{tabular}{|c|c|c|c|c|c|c|c|c|c|c|}
\hline \multirow{2}{*}{\multicolumn{2}{|c|}{ Propósito }} & & \multicolumn{4}{|c|}{ México } & \multicolumn{4}{|c|}{ Internacional } \\
\hline & & $\overline{0}$ & 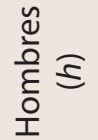 & $\circ \stackrel{\Sigma}{5}$ & 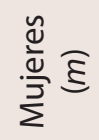 & $\circ{ }^{E}$ & 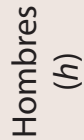 & $\circ \stackrel{\Sigma}{\Xi}$ & 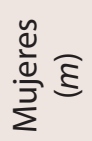 & $\circ \stackrel{\Sigma}{\xi}$ \\
\hline \multicolumn{2}{|l|}{$\begin{array}{l}\text { PS6 } \\
\text { Total=369 } \\
(11.61 \%)\end{array}$} & 369 & 239 & 64.77 & 108 & 29.27 & 13 & 3.52 & 9 & 2.44 \\
\hline \multirow{3}{*}{$\begin{array}{l}\text { PS1 } \\
\text { Total=248 } \\
(7.80 \%)\end{array}$} & PS1A & 178 & 117 & 65.73 & 50 & 28.09 & 9 & 5.06 & 2 & 1.12 \\
\hline & PS1B & 51 & 38 & 74.51 & 13 & 25.49 & 0 & 0 & 0 & 0 \\
\hline & PS1C & 19 & 11 & 57.89 & 8 & 42.11 & 0 & 0 & 0 & 0 \\
\hline \multicolumn{2}{|l|}{$\begin{array}{l}\text { PS3 } \\
\text { Total=34 } \\
(1.07 \%)\end{array}$} & 34 & 14 & 41.18 & 14 & 41.18 & 4 & 11.76 & 2 & 5.88 \\
\hline \multicolumn{2}{|l|}{$\begin{array}{l}\text { PS2 } \\
\text { Total=24 } \\
(0.75 \%)\end{array}$} & 24 & 8 & 33.33 & 13 & 54.17 & 2 & 8.33 & 1 & 4.17 \\
\hline \multicolumn{2}{|l|}{$\begin{array}{l}\text { PS7 } \\
\text { Total=19 } \\
(0.60 \%)\end{array}$} & 19 & 16 & 84.21 & 3 & 15.79 & 0 & 0 & 0 & 0 \\
\hline \multicolumn{2}{|l|}{$\begin{array}{l}\text { PS4 } \\
\text { Total=13 } \\
(0.41 \%)\end{array}$} & 13 & 5 & 38.46 & 8 & 61.54 & 0 & 0 & 0 & 0 \\
\hline \multicolumn{2}{|l|}{ Total } & 3,179 & 2,063 & 64.89 & 1,074 & 33.78 & 28 & 0.88 & 14 & 0.44 \\
\hline
\end{tabular}

Nota: Elaboración propia, con base en la muestra de 3179 docentes que aplicaron para el periodo sabático durante los años académicos 2012-2018.

En el diagrama de Pareto de la Figura 5, se observa que durante los años académicos del 2012-2018 en el TecNM, los productos académicos más significativos producidos por el profesorado, es decir, los efectos que contribuyen en un $80 \%$ son la realización de apuntes, libros de texto y estadías; de estos tres, más del $80 \%$ acumulado, se encuentra representado por los apuntes obtenidos en la aplicación del PS5A. Este programa académico tiene la mayor representativa anual de los productos, con un promedio de $37.87 \%$ de apuntes, los siguientes programas en orden de representatividad son los PS5B y PS6, que contribuyen en promedio con $34.10 \%$ de libros de texto y $11.61 \%$ de estadías, respectivamente. Otro programa menos representativo es el PS1A, que contribuye con un promedio de $5.60 \%$ de investigación científica. Los otros 14 programas $(77.77 \%$ del total de programas) no representan una producción considerable respecto al PS5A y no se aprecia ningún crecimiento en ellos. 
http://doi.org/10.15359/ree.24-3.4

http://www.una.ac.cr/educare

educare@una.cr

Figura 5: Diagrama de Pareto de los productos de los programas académicos del sabático del TecNM durante los años académicos $2012-2018$

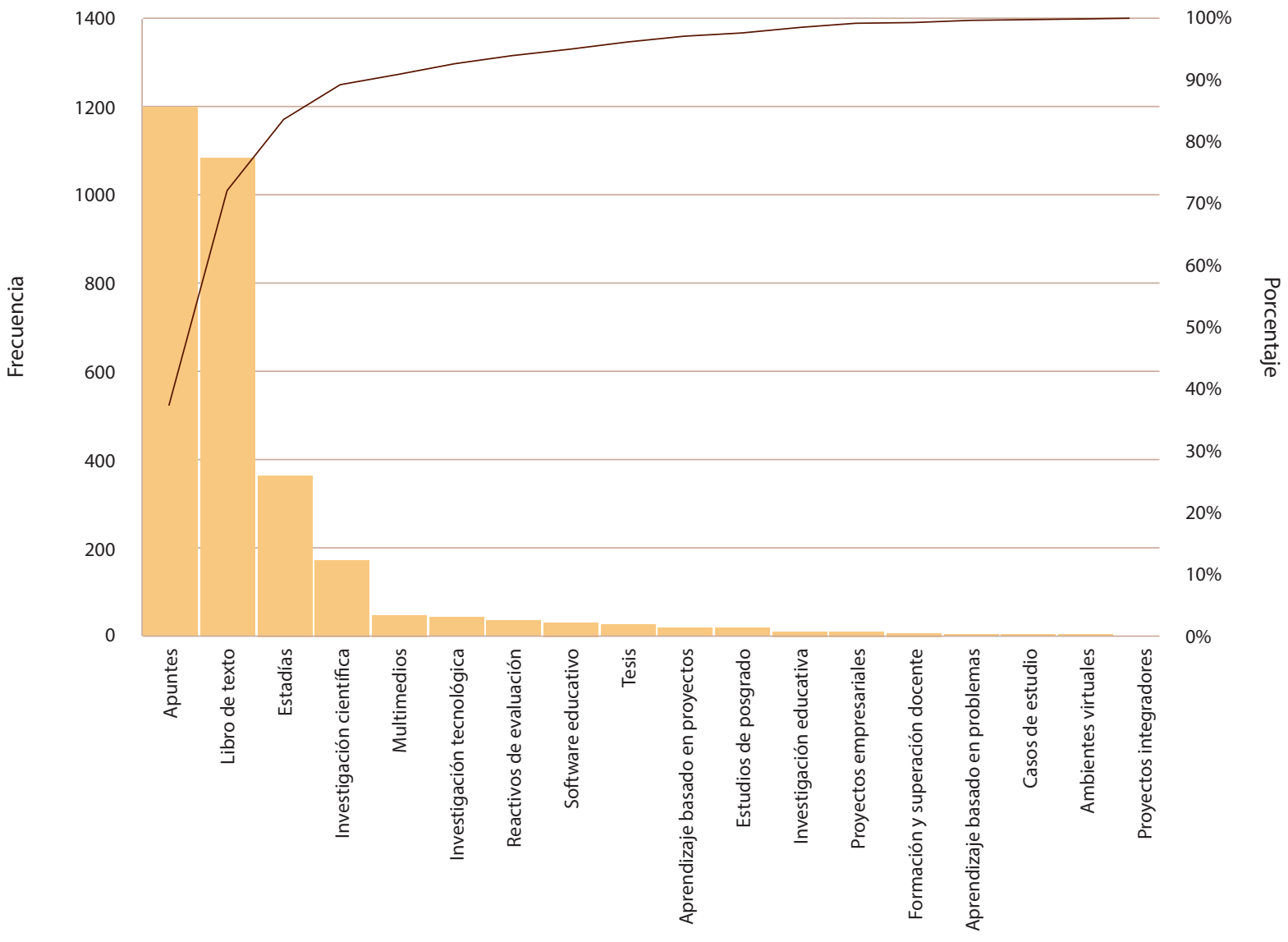

Programas académicos

Nota: Elaboración propia, con base a la distribución del profesorado del periodo sabático durante los años académicos 2012-2018 (Tabla 6).

\section{Discusión}

En el estudio de los años académicos 2012-2018, la autorización del periodo sabático a las $n=3179$ docentes de tiempo completo del TecNM muestra fluctuaciones considerables entre los años analizados (rango de 429 a 574, excluyendo el año 2018 por considerar solo el primer semestre), pero las cantidades mostradas dan certeza de que el sabático, año con año, se otorgó en el TecNM, lo cual toma relevancia desde dos aspectos: la normatividad y los recursos económicos. En la investigación se mencionó que desde el propio modelo educativo y del reglamento del personal docente del TecNM, el propósito del periodo sabático se encuentra establecido, por lo que este hecho garantiza que se siga otorgando al profesorado este 
http://doi.org/10.15359/ree.24-3.4

beneficio. Por otro lado, aunque no se menciona nada respecto a lo económico, el hecho de que, en el reglamento del personal docente se establezca como un derecho que dice: "El año sabático consiste en separarse durante un año de sus labores docentes con goce de sueldo..." (SEP, 1982, p. 35), supone que la administración del TecNM destina un recurso económico importante para el sueldo promedio anual de las 498 personas que ejercen este beneficio para su formación profesional; de acuerdo con la última minuta SEP-SNTE, la categoría más baja del personal docente de tiempo completo de enseñanza superior tiene un sueldo tabular de $\$ 7$ 610.70 pesos mexicanos, lo cual supone una inversión anual promedio mínima de \$3 790 128.6 pesos mexicanos para mantener la calidad del profesorado en la estrategia del periodo sabático (Secretaría de Educación Pública [SEP ] y Sindicato Nacional de Trabajadores de la Educación [SNTE], 2019). Los aspectos normativo y económico considerados, confirman que el TecNM es una institución de educación superior que destina una inversión económica importante para el periodo sabático, con la finalidad de fortalecer la formación académica de su profesorado y ofrecer una calidad de educación superior en México.

Considerando que el TecNM es una institución de educación superior tecnológica, orientada a la formación del área de ingeniería, la participación de 1088 mujeres es significativa, la cual representa el $10.60 \%$ del total del profesorado de tiempo completo del TecNM (10 264 personas) y un $34.22 \%$ respecto del profesorado que realizó el sabático. Esto representa una oportunidad para que el TecNM proponga nuevas políticas, lineamientos o procedimientos respecto del sabático, que impulsen a la mujer en la participación de este programa de formación académica.

Es llamativo que la edad promedio del profesorado participante en el sabático sea $55.74 \pm$ 7.92 años, y que la mayor cantidad de solicitudes la realizaron personas de 60 años de edad. De acuerdo con Albornoz (1998), una edad de 50 años representa un riesgo para la institución, debido a que el profesorado se puede jubilar. Esto puede ser consecuencia de dos posibles aspectos: el primero de ellos, que se confirma con la escasa participación de 5 personas en el rango de edad de 25 a 35 años, es que los requisitos para participar en el sabático no son flexibles o solo el personal con mayor antigüedad de servicio los cumple; por ejemplo, en el estudio realizado en la Universidad de Indiana por Sorcinelli (1986), uno de los principales hallazgos fue que las personas entrevistadas recomendaron mayor flexibilidad en el procedimiento del sabático. El segundo aspecto es que no se esta trabajando en un programa de relevo generacional al interior de las instituciones del TecNM, el cual permita conformar nuevo personal docente en la formación académica del sabático; en otras palabras, sería crear "un programa de formación docente que ofrezca becas a estudiantes de excelentes condiciones académicas, de tal manera que puedan dedicarse de lleno a sus estudios de posgrado y cuando los finalicen, puedan participar exitosamente en los concursos docentes" (Martínez Collantes, 1999, p. 63). 
http://doi.org/10.15359/ree.24-3.4

http://www.una.ac.cr/educare

educare@una.cr

Como parte de los beneficios del sabático, el profesorado tiene la oportunidad de vivir nuevas experiencias y conocer la cultura, religión e ideología de otros países, así como actualizarse en la tecnología de vanguardia visitando laboratorios altamente especializados (Iravani, 2011; Sorcinelli, 1986; Zahorski, 1994); en cambio, al comparar el profesorado que realizó su sabático en México frente a los que eligieron realizarlo en el extranjero, solo el 1.32\% (42 personas respecto de la muestra $n=3$ 179) estuvo en otros países, lo cual implica que la movilidad del profesorado es limitada a través del sabático. Además, si consideramos que la edad promedio es de $55.74 \pm 7.92$ años, es lógico pensar que la edad del profesorado puede ser una de las razones que limita la movilidad al extranjero. Sería interesante realizar una investigación cuantitativa y cualitativa de las causas por los cuales el $98.68 \%$ de la muestra utilizada en este artículo no desea experimentar un cambio cultural en otro país.

En cuanto a los programas académicos establecidos en los propósitos del sabático del TecNM, los resultados obtenidos pudieran ser indicativos de que el profesorado utiliza el sabático como un espacio de receso o descanso, en lugar de asumir nuevos retos y cambios encaminados a su actualización o superación académica. Este planteamiento se basa en el hecho de que anualmente, en promedio, el $71.97 \%$ de los productos académicos se derivan de los PS5A y PS5B; además, estos apuntes y libros de texto que representan el $37.87 \%$ y $34.10 \%$, respectivamente, están orientados al desarrollo de contenidos educativos establecidos en las asignaturas, que regularmente el profesorado ha impartido por años y tiene material desarrollado, lo cual implicaría que antes de solicitar el sabático el profesorado ya tiene un avance del producto final que entregará al finalizar su sabático.

El programa académico que en menor porcentaje destaca es el PS6-Estadías, que tiene una contribución anual en promedio del $11.61 \%$ de los productos académicos; este programa, al realizarse en la industria, demanda en el profesorado un proceso de adaptación acorde con los requerimientos del entorno, que muchas veces en las universidades no se contempla, pero tiene un gran beneficio para la comunidad estudiantil, debido a que el profesorado puede transmitir experiencias, conocimiento de nuevas tecnología y, principalmente, las competencias que el futuro estudiantado egresado debe mostrar en los procesos de reclutamiento que realiza la empresa. Otro programa académico a mencionar, por el tipo de educación superior tecnológica que ofrece el TecNM, es el PS1A, el cual contribuye anualmente en promedio un $5.60 \%$ de la producción total y el profesorado realiza investigación científica; aunque podría pensarse que este programa debería tener una mayor participación del profesorado, sobre todo en una institución del corte del TecNM.

Los datos obtenidos revelan que los otros catorce programas académicos no tienen relevancia al contribuir en la producción total de los productos esperados por el TecNM, considerando que cada uno de ellos no supera el promedio anual del $1.67 \%$ de los productos académicos, lo cual, desde el punto de vista de personas participando, se puede afirmar que es muy bajo en cada uno de ellos. Esto nos hace reflexionar y poner en consideración, si es 
http://doi.org/10.15359/ree.24-3.4

pertinente cancelarlos para los siguientes años académicos o diseñar estrategias de captación para que el profesorado tenga una mayor participación; por otro lado, cancelar estos catorce programas implicaría limitar la flexibilidad del periodo sabático del TecNM, debido a que beneficios como la actualización profesional y docente, redes profesionales y componente de rejuvenecimiento y renovación no se reflejarían en el profesorado a su regreso del sabático.

\section{Conclusiones}

El TecNM, como uno de los más grandes sistemas de México, es una institución que impulsa la formación académica de su profesorado, para mantener una planta docente y de investigación de calidad en el campo del desarrollo científico y tecnológico; para el logro de ello, el TecNM tiene, como una de sus políticas principales, el promover el periodo sabático de seis o doce meses para la realización de investigación, estudios formales de nivel posgrado y todas aquellas actividades académicas que coadyuven a la superación académica del profesorado. Durante este tiempo, el profesorado se separa de sus labores docentes, disfruta el beneficio del goce de sueldo y no tiene pérdida de sus derechos (SEP, 1982). Este sabático, de acuerdo con el TecNM (2016, p. 8), tiene siete propósitos:

1. Investigación científica, tecnológica y educativa.

2. Estudios de posgrado, especialización, actualización y actividades posdoctorales.

3. Elaboración de tesis para la obtención del grado.

4. Formación y superación docente.

5. Elaboración de material y auxiliares didácticos para la enseñanza.

6. Estadías en el sector productivo o en centros de investigación o instituciones de educación superior: nacionales o internacionales.

7. Desarrollo de proyectos empresariales.

A partir de una muestra de $n=3179$ que representan el $30.97 \%$ del total del profesorado con plaza base de tiempo completo, que solicitaron el sabático desde el año académico 2012 al primer semestre de 2018, se encontraron hallazgos, los cuales se enuncian como fortalezas y áreas de oportunidad.

\section{Fortalezas:}

1) Dieciocho programas académicos que se ofrecen al profesorado para realizar el periodo sabático: diseño y producción de materiales didácticos para la enseñanza como documentos (apuntes, libros y reactivos), aprendizaje (proyectos integradores, 
http://doi.org/10.15359/ree.24-3.4

http://www.una.ac.cr/educare

educare@una.cr

estrategias basada en problemas o proyectos, y casos de estudio), y modalidad en línea (software, multimedia y ambientes virtuales); investigación (científica, tecnológica y educativa); estudios de nivel posgrado (los estudios pueden ser de especialización, maestría y doctorado); tesis; formación y superación docente; estadías; y proyectos empresariales (TecNM, 2016). Los de mayor de relevancia, que representan en promedio anual el $89.18 \%$ de los productos académicos son los apuntes (37.87\%), libros de texto (34.10\%), estadías (11.61\%) e investigación científica (5.60\%).

2) $34.22 \%$ (1 088) de la muestra ( $n=3$ 179) empleada para este estudio son mujeres académicas del TecNM y el 65.78\% (2 091) son hombres.

3) 498 personas (4.85\%) del total del profesorado con base de tiempo completo del TecNM son beneficiadas para un sabático de manera anual. Esto quiere decir, de manera indirecta, que la institución invierte un recurso económico importante en su profesorado para su formación académica.

4) La parte norte de México (zonas noreste-y noroeste) tienen la mayor participación del profesorado (543 mujeres y 969 hombres que representan el $17.08 \%$ y $30.48 \%$ de la muestra $n=3179$ ), y es la zona noreste la que tiene la mayor participación del país con un total de 964 personas que corresponde al 30.32\%.

5) $71.98 \%$ (2 288) de la muestra ( $n=3$ 179) elabora apuntes, manuales de prácticas o un libro durante su sabático, lo cual fortalece la publicación de materiales para la impartición de cursos. Ello implica que los centros de información o bibliotecas de los institutos adscritos al TecNM mantienen un acervo bibliográfico especializado y adaptado a los contenidos educativos de los programas de las asignaturas de las diversas ingenierías que ofrece la institución, de manera ideal se espera que esos productos incorporen la experiencia del sabático del profesorado.

6) $88.44 \%$ de eficiencia terminal (2 357 personas en estado de "liberado" de un total de 2 665). Las 514 personas de las convocatorias del segundo semestre 2017 y el primer semestre 2018 están en proceso de conclusión. Por tanto, la eficiencia terminal se puede considerar alta y sugiere que la inversión económica realizada por el TecNM, tiene un retorno de impacto directo en la comunidad de la institución mayor al $80 \%$.

\section{Áreas de oportunidad:}

1) Nivelar la participación en México, debido a que solo los diez Estados de Chihuahua, Michoacán, Veracruz, Tamaulipas, Sonora, Sinaloa, Durango, Baja California, Coahuila y Yucatán tienen el $60.27 \%$ de la participación del total de la muestra ( $n=3$ 179), donde Chihuahua es el Estado con mayor participación de 322 personas que equivale al $10.22 \%$. 
http://doi.org/10.15359/ree.24-3.4

2) Promover en las generaciones más jóvenes, su formación académica a través del sabático, debido a que el 36.7\% (1 167) del profesorado tienen una edad media de $55.74 \pm 7.92$ años, con lo cual se tiene el riesgo institucional de que el profesorado se jubile a su regreso y no haya un beneficio para las comunidades educativas. Considerando que las personas que más solicitaron un sabático tienen una edad de 60 años, sugiere que se tenga que pensar en las políticas académicas del sabático que impulsen la participación de personas de menor edad y formen cuadros académicos que revitalicen la institución.

3) Impulsar la movilidad del profesorado y la expansión de redes profesionales con otras instituciones nacionales e internacionales, debido a que el $85.91 \%$ (2 695) realiza su sabático en su propia institución en la cual desempeñan sus actividades docentes. Para el caso de la movilidad al extranjero, los datos proporcionan una evidencia contundente de que la movilidad del profesorado del TecNM es prácticamente nula y, por lo tanto, limita el posicionamiento de la institución en el plano internacional.

4) Nivelar la participación del profesorado en los programas académicos para realizar el sabático, dado que el $89.18 \%$ (2 835) selecciona los programas académicos orientados a documentación (apuntes y libros), estadías (instituciones educativas o empresas) e investigación (solo la científica).

\section{Recomendaciones}

Es importante reflexionar sobre las variables o aspectos que puedan impactar en la implementación del sabático, por ello se proponen cuatro recomendaciones a considerar para futuras investigaciones en el sabático del TecNM.

1. Actualizar el reglamento del personal docente y ajustarlo en cuanto a las políticas académicas de un nuevo modelo educativo del TecNM, que consolide la formación académica del profesorado.

2. Construir un repositorio institucional para la difusión de los productos académicos en México e impulsar el registro de propiedad intelectual.

3. Realizar un seguimiento y evaluación de los productos académicos realizados por el profesorado que aplicó al sabático, con la finalidad de vigilar el retorno de la inversión económica realizada por el TecNM.

4. Flexibilizar los procedimientos de aplicación para el profesorado interesado en realizar su sabático en el extranjero, preferentemente en la investigación, estadías y proyectos empresariales. 
http://doi.org/10.15359/ree.24-3.4

http://www.una.ac.cr/educare

educare@una.cr

Se concluye que el periodo sabático del TecNM es una estrategia de formación académica del profesorado, en la cual sus políticas académicas están muy completas por ofrecer dieciocho programas académicos, y que, económicamente, requiere una inversión importante por parte de la administración.

\section{Agradecimientos}

Esta investigación se ha realizado con el apoyo otorgado por el Tecnológico Nacional de México, a través de la disponibilidad y aportes de la Dirección de Docencia e Innovación Educativa, así como la información solicitada para llevar a cabo este estudio.

\section{Referencias}

Abascal Gaytán, L.y Abascal Gaytán, R. P. (2016). Año sabático en el Instituto Politécnico Nacional frente al modelo educativo, estudio de caso escuela superior de turismo. Red Internacional de Investigadores en Competitividad, 10, 1099-1113. https://goo.gl/ADuxPi

Academic Senate for California Community Colleges. (2007). Sabbaticals: Benefitting faculty, the Institution, and students. https://goo.gl/xjA94c

Albornoz, O. (1998). Acerca de la educación superior en Venezuela. Revista Venezolana de Economía y Ciencias Sociales, 4(2-3), 79-120. http://www.ucv.ve/estructura/facultades/ facultad-de-ciencias-economicas-y-sociales/institutos/inst-de-investig-economicas-ysociales-iies/revista-venezolana-de-economia-y-ciencias-sociales.html

Arribas Urrutia, A. (2007). El equilibrio personal y profesional como valor de la cultura corporativa. Organicom, 4(6), 48-63. https://doi.org/10.11606/issn.2238-2593.organicom.2007.138925

Bustamante, R., Cadena, Á. y Gauthier, A. (2004). La investigación y los posgrados en la facultad de ingeniería. Revista de Ingeniería, 20, 76-79. https://ojsrevistaing.uniandes.edu.co/ojs/ index.php/revista/article/view/424/600

Carr, A. E. y Tang, T. L.-P. (2005). Sabbaticals and employee motivation: Benefits, concerns, and implications. Journal of Education for Business, 80(3), 160-164. https://doi.org/10.3200/ JOEB.80.3.160-164

Cervantes, M. (2005). Las ventajas de la empresa flexible. Universia Business Review, 5, 112-119. https://dialnet.unirioja.es/ejemplar/102516

Crosby Eells, W. y Hollis, E. V. (1962). Sabbatical leave in american higher education: Origin, early history and current practices (Bulletin No. 17). U.S. Government Printing Office. https://goo. $\mathrm{gl} / \mathrm{o} 58 \mathrm{xFF}$ 
http://doi.org/10.15359/ree.24-3.4

Decreto que crea el Tecnológico Nacional de México. (23 de julio de 2014). Diario Oficial de la Federación, Tomo 730, No. 21. https://goo.gl/TJEuGU

Dirección General de Educación Superior Tecnológica. (2012). Modelo educativo para el siglo XXI: Formación y desarrollo de competencias profesionales. Autor. http://www.dgest.gob.mx/ modeloeducativo/modeloeducativo.pdf

Diversity Best Practices. (2018). Research report: Returnships, apprenticeships \& sabbaticals. Worklife benefits to attract and retain talent. Autor. https://goo.gl/k3obga

Domínguez Martínez, J. M., Fernández Vílchez, B. y Pedrosa Cruzado, A. (2011). Medidas para el ahorro de costes laborales: Un análisis comparativo. Extoikos, 2, 47-53. https://goo.gl/ zjD4bc

Easteal, P. y Westmarland, N. (2010). The virtual sabbatical: A pioneering case study. Innovative Higher Education, 35(5), 297-311. https://doi.org/10.1007/s10755-010-9153-9

Hernández Sampieri, R., Fernández Collado, C. y Baptista Lucio, P. (2014). Metodología de la investigación (6. ${ }^{\mathrm{a}}$ ed.). McGraw-Hill.

Iravani, H. (2011). Analyzing impacts of sabbatical leaves of absence regarding faculty members, University of Tehran. Procedia - Social and Behavioral Sciences, 15, 3608-3615. https://doi. org/10.1016/j.sbspro.2011.04.343

Kang, B. y Miller, M. T. (1999). An overview of the sabbatical leave in higher education: A synopsis of the literature base. https://goo.gl/geVt8n

Kimball, B. A. (1978). The origin of the Sabbath and its legacy to the modern sabbatical. The Journal of Higher Education, 49(4), 303-315. https://doi.org/10.1080/00221546.1978.1178 $\underline{0380}$

Martínez Collantes, J. (1999). El relevo generacional del personal docente universitario [Editorial]. Revista de la Facultad de Medicina Universidad Nacional de Colombia, 47(2), 63. https:// sci-hub.se/https://revistas.unal.edu.co/index.php/revfacmed/article/view/19440

Martín-Sempere, M. J., Rey-Rocha, J. y Plaza, L. M. (1999). Movilidad temporal de investigadores y cooperación científica internacional. Las estancias de los sabáticos latinoamericanos en España. Interciencia: Revista de Ciencia y Tecnología de América, 24(2), 107-111. https://goo. $\mathrm{gl} / \mathrm{jySq} 3 \mathrm{~m}$

McDearmid, R. C. (2014). Time Out and Time Off: A Systematic Review of the Benefits of Sabbatical [Tesis de maestría]. Universidad de la Isla del Príncipe Eduardo, Canadá. https://www. islandscholar.ca/islandora/object/ir\%3A9546/datastream/PDF/view 
http://doi.org/10.15359/ree.24-3.4

http://www.una.ac.cr/educare

educare@una.cr

Ossa Londoño, J. (1999). Para soñary construir la universidad (Cap. 6). Editorial Copiyepes. https:// goo.gl/ncSMGx

Parent Jacquemin, J. M. (1998). El año sabático. Universidad Autónoma del Estado de México.

Pereira de Homes, L. y Ochoa Henríquez, H. (2002). Políticas y estrategias para la formación del personal académico de la Universidad del Zulia en la década de los noventa. Reencuentro, 34, 41-53. https://www.redalyc.org/articulo.oa?id=34003404

Pereira de Homes, L. y Suárez Amaya, W. (2003). El beneficio del año sabático como estrategia de formación académica. Revista Venezolana de Ciencias Sociales, 7(1), 88-100.

Ramírez Bacca, R. (2013). Ser historiador en Colombia es el más puro resultado de la casualidad. HiSTOReLo. Revista de Historia Regional y Local, 5(9), 360-371. https://doi.org/10.15446/ historelo.v5n9.37248

Rivera Mendoza, M., Salinas Montes, J. y Silva Carballido, H. E. (2009). Una mirada a la participación de la mujer en los programas formativos del Departamento de Posgrado e Investigación de SEIEM. Memoria del X Congreso Nacional de Investigación Educativa (pp. 1-12). Consejo Mexicano de Investigación Educativa. https://goo.gl/2RQsJq

Ruiz Pérez, A. (2012). Año sabático para los profesores del Perú, hoy o nunca. UCV-HACER. Revista de Investigación y Cultura, 1(1), 68-73. https://goo.gl/hyHHRH

Sarason, S. B. (1990). The predictable failure of educational reform: Can we change course before It's too late? Jossey-Bass.

Secretaría de Educación Pública. (1982). Título cuarto. Año sabático. Capítulo único del año sabático. En Reglamento interior de trabajo del personal docente de los Institutos Tecnológicos. Autor. http://its.mx/pdf/reg docente.pdf

Secretaría de Educación Pública (2018). Manual de procedimientos del Tecnológico Nacional de México. Autor. http://dgest.gob.mx/images/areas/difusion0101/Difusion0101/2018/ NOVIEMBRE/DOCUMENTOS/23 PLANEACI\%C3\%93N /Manual de Procedimientos del Tecnol\%C3\%B3gico Nacional de M\%C3\%A9xico 2.pdf

Secretaría de Educación Pública y Sindicato Nacional de Trabajadores de la Educación. (15 de mayo, 2019). Minuta. https://undesintec.mx/homologados2019.pdf

Sima, C. M. (2000). The role and benefits of the sabbatical leave in faculty development and satisfaction. New Directions for Institutional Research, 2000(105), 67-75. https://doi. org/10.1002/ir.10506 
http://doi.org/10.15359/ree.24-3.4

Sima, C. M. y Denton, W. E. (1995, noviembre). Reasons for and products of faculty sabbatical leaves. Trabajo presentado en el Annual Meeting of the Association for the Study of Higher Education, Orlando, Florida. https://goo.gl/jjE55w

Sorcinelli, M. D. (1986, abril). Sabbaticals and Leaves: Critical events in the careers of faculty. Trabajo presentado en el Annual Meeting of the American Educational Research Association, San Francisco, California. https://eric.ed.gov/?id=ED270014

Tecnológico Nacional de México. (2016). Lineamientos metodológicos de los programas susceptibles de ser desarrollados en el periodo sabático del Tecnológico Nacional de México. Autor. $\quad$ http://www.dgest.gob.mx/images/areas/docencia01/Libre para descarga/ Sabatico/Lineamientos P Sab\%C3\%A1tico TecNM 2016.pdf

Tecnológico Nacional de México. (2018a). Anuario Estadístico 2018. Autor. https://www.tecnm. mx/pdf/ANUARIO ESTADISTICO 2018.pdf

Tecnológico Nacional de México. (2018b).Propuesta del modeloeducativo del Tecnológico Nacional de México. Documento de trabajo: Innovar para innovar. Autor.https://nme.tepic.tecnm.mx/ uploads/documentos/3 ME TecNM EJECUTIVO SOCIALIZAR EN FOROS 110818.pdf

Vargas Acosta, J. (2016). Las redes de maestros: Formas de organización para autoafirmarse en ejercicio de la profesión docente. Magazín Aula Urbana, 104, 3. https://goo.gl/wq2twt

Zahorski, K. J. (1994). The sabbatical mentor: A practical guide to successful sabbaticals. Anker Publishing Company. 